\title{
MARKET POWER AND INFORMATION REVELATION IN DYNAMIC TRADING
}

\author{
PIERO GOTTARDI \\ ROBERTO SERRANO
}

CESIFO WORKING PAPER NO. 1300

CATEGORY 9: INDUSTRIAL ORGANISATION

OCTOBER 2004

\footnotetext{
An electronic version of the paper may be downloaded

- from the SSRN website:

www.SSRN.com

- from the CESifo website:

www.CESifo.de
} 


\title{
MARKET POWER AND INFORMATION REVELATION IN DYNAMIC TRADING
}

\begin{abstract}
We study a strategic model of dynamic trading where agents are asymmetrically informed over common value sources of uncertainty. There is a continuum of buyers and a finite number $\mathrm{n}$ of sellers. All buyers are uninformed, while at least one seller is privately informed about the true state of the world. When $\mathrm{n}=1$, full information revelation never occurs in equilibrium and the only information transmission happens in the first period. With $n>1$ the outcome depends both on the structure of the sellers' information and, even more importantly, on the intensity of competition allowed by the trading rules. When there is intense competition (absence of clienteles), information is fully and immediately revealed to the buyers in every equilibrium for $n$ large enough, regardless of the number of informed sellers. On the other hand, for trading arrangements characterized by less intense forms of competition (presence of clienteles), for any $\mathrm{n}$ we always have equilibria where information is never fully revealed. Moreover, in that case, when only one seller is informed, for many parameter configurations there are no equilibria with full information revelation, even for large $n$.
\end{abstract}

JEL Code: C72, C78, D82, D83.

Keywords: asymmetric information, information revelation, dynamic trading, oligopolistic competition, clienteles.

\author{
Piero Gottardi \\ Department of Economics \\ University of Venice \\ Cannaregio 873 \\ 30121 Venice \\ Italy \\ gottardi@unive.it
}

\author{
Roberto Serrano \\ Department of Economics \\ Brown University \\ Providence, RI 02912 \\ USA \\ roberto_serrano@brown.edu
}

We are grateful to Jordi Caballé, Jean-Francois Mertens, Claudio Mezzetti, Mike Peters, Xavier Vives, as well as seminar participants at Pompeu Fabra, UAB, Copenhagen, IIES, Sevilla, Jerusalem, Iowa State, British Columbia, Ohio State, IAS-Princeton and the SAET Conference in Rhodos for useful comments and discussions. Part of the work for this paper was carried out when the first author was visiting Brown University and CES, and when the second author was visiting the Institute for Advanced Study; we wish to thank the three institutions for their warm hospitality and support. Financial support from MIUR and CNR to the first author and from the Alfred P. Sloan Foundation, Deutsche Bank and the NSF under grant SES-0133113 to the second author is gratefully acknowledged. 


\section{Introduction}

This paper studies a strategic model of dynamic trading where: (1) non-negligible agents interact with negligible ones -a finite number of sellers serve a continuum of buyers, and (2) there is asymmetric information about the quality of the good being traded, an instance of common values uncertainty. All buyers are uninformed, while at least some sellers are informed. ${ }^{1}$ In this situation the "size", or the market power of a seller is determined along two dimensions: his market share, as in standard oligopoly, and his informational status, i.e., whether he is informed or not. Furthermore, trade extends potentially over infinitely-many periods; hence, current actions may have important effects on a trader's "size" in the future.

When no trader has any appreciable market power, the most often used equilibrium notion in economies with common values asymmetric information is given by the rational expectations equilibrium (REE). ${ }^{2}$ Like Walrasian equilibria, REE do not rely on a specific trading mechanism (in this sense we can say they are institution-free), but simply on a price function specifying a price in each state, taken as given by all traders. The economy is "competitive", although not exactly in a standard sense. The observation of a realized price from the equilibrium price function not only defines the agents' trading possibilities in that state, but also aggregates and disseminates information, allowing uninformed traders to learn about the true state. In fact, REE prices generically fully reveal all the agents' private information, without any delay. Not specifying the trading rules is no doubt an advantage in terms of robustness, but the "black box" feature of the price function leaves open an important question: how does the private information held by some traders get incorporated into the REE price function?

To address this question, it is imperative to investigate the strategic foundations of REE. This requires the specification of trading procedures where the transmission of information among the agents in the market is explicitly modelled. This issue has already received some attention in the literature, primarily within the set-up of static models, and of other trading mechanisms, like auctions or market games, where it was shown that the non-exclusivity of traders' information plays an important role in determining whether convergence to REE obtains when the number of traders increases. ${ }^{3}$

\footnotetext{
${ }^{1}$ Having no information on the buyers' side is a simplifying assumption, though in line with the oligopolistic literature treating all consumers symmetrically.

${ }^{2}$ See Radner (1982) for a survey.

${ }^{3}$ See Section 7 for further details on the related literature.
} 
Rather than on the information structure, this paper will focus on the properties of the trading mechanism that may facilitate or hinder revelation. In particular we identify two such properties: the transparency of the market (i.e. the extent to which market prices are observable and information over trades is disclosed to other traders), and the degree of competition allowed by the trading rules (i.e. the ease with which buyers are free, at any point in time, to choose whom to buy from).

The importance of these factors stems from considering the negative results on convergence and information revelation obtained by Wolinsky (1990) and Blouin and Serrano (2001) among others, which are independent of the information structure. These authors consider economies with infinitely many trading dates where each period agents chosen from a continuum are randomly matched in pairs and within each pair they bargain over the terms of trade (rejection of all offers and hence refusal to trade is always possible). In this set-up it is found that even with a continuum of traders, many of them informed (hence with no exclusivity of information), and in the limit as discounting goes to zero, ${ }^{4}$ a sizeable portion of uninformed traders transact at prices that are ex post not individually rational.

In the trading mechanism considered in these pairwise meetings papers both the degree of transparency of the market and the degree of competition are fairly limited:

(A) No transparency: agents have no access to any public market signals/prices, nor do they have any information over the terms at which trade occurred in the past in the market (each trader observes and remembers only his own history of trades).

(B) Local monopoly: each pairwise meeting (which can be thought of as a buyer visiting a particular store) represents a "local monopoly" in its own right, in the sense that in that period the buyer can buy the good only from that store. Of course, he can walk out and visit a different store, but this comes at a cost, as captured by discounting. Likewise, a seller cannot get instantaneous, discrete increases in his market share because of the face-toface trading interaction.

In this light, one criticism of the pairwise meetings papers is that they have gone too far in limiting the possibilities of information transmission among traders.

\footnotetext{
${ }^{4}$ Discounting is the cost of acquiring information through price sampling.
} 
It is in fact plausible to model a situation in which traders receive some market signal. In this paper we shall assume that each period buyers get to observe all prices posted by sellers before they agree to buy the good - high transparency. ${ }^{5}$ Still, as our results will show, even if one removes friction (A) by having full observability of prices, restrictions to competition similar to (B) may suffice to prevent information revelation.

Our approach to better understand the mechanisms behind information revelation will be to develop models that "lie between" the pairwise meetings market and REE. Accordingly, we shall analyze variants of a model with several competition rules and information structures, to identify the conditions under which information revelation occurs. In each case, we will provide a complete characterization of equilibria and analyze their revelation and efficiency properties. The specifics of our model follow.

We study a market for an indivisible good of uncertain quality with infinitely many trading dates. All the units of the good in each period are of the same quality, either high or low. Thus, there are two states of the world: $H$ and $L$. There is a continuum of buyers, all of them uninformed about the state. Among the finite number $n$ of sellers, at least one is informed. Every period, each seller simultaneously chooses whether to post a high or a low price for the good. ${ }^{6}$ Upon observing the prices posted in a period, every buyer can either refuse to buy, and be present again in the market the next period, or accept to buy from one of the sellers at the price he posted, and leave the market.

As a building block in our analysis, we consider first the case of an informed monopolist $(n=1)$. We find that at equilibrium information revelation is minimal. He reveals some information only when the buyers' prior belief is too pessimistic about the state being $H$; in this case he reveals only part of his information and only in the first period. Thus continued randomization is not optimal: once the buyers are convinced that consuming the good brings them a non-negative expected utility, the single informed trader has no further incentive to reveal his information. The presence of competitors among the sellers will change this result a great deal.

\footnotetext{
${ }^{5}$ See Peters (1991) for a related model, where agents' matching is non-random because it is affected by the posted prices.

${ }^{6}$ The restriction of having only two possible prices strips down the model of unnecessary complications (in particular, by limiting the role of the beliefs of the uninformed) and allows to provide a complete characterization of all the equilibrium outcomes. As argued in Appendix B, the substance of our results remains valid even if this restriction is dropped.
} 
The paper proceeds to analyze the case of oligopoly under two extreme information structures: (i) all sellers are informed: information is thus non-exclusive and each seller is "informationally small" - see Gul and Postlewaite (1992); and (ii) only one seller is informed: his "informational size" is then large relative to the other agents. ${ }^{7}$ More important qualitative differences are found in the equilibrium outcomes corresponding to two alternative sets of trading rules, characterized by different intensities of price competition. In the first one - denoted as the model without clienteles - each buyer is free to buy the good from the seller that is offering it at the lowest price (as in the classic Bertrand model). On the other hand, in the model with clienteles any seller can only reach within each period a fraction of all buyers (resembling less extreme forms of competition, such as Cournot or Bertrand with capacity constraints).

We show that in the model without clienteles, information is fully and immediately revealed in every equilibrium for large enough $n$, no matter what is the structure of the information. The intensity of price competition implies that the benefit of expanding one's market share by posting a low price - in state $L$ - is too attractive, when the number of sellers is large enough, even though this means to dissipate any current and future informational rent. This proves to be the case not only with many informed sellers, for whom "collusion" to hide their information is fragile and does not survive when $n$ is large enough, but also when there is just one informed seller, who prefers to give up his exclusive information in order to increase his sales.

The situation is rather different in the model with clienteles. Although when all sellers are informed there is again an equilibrium with full revelation because of the non-exclusivity of information, a collusive equilibrium where some information is not revealed at any date exists as well, whatever the number of sellers. Moreover, when only one seller is informed, for many parameter values there are no revealing equilibria, even for arbitrarily large $n$.

The lack of information revelation in some equilibria of the model with clienteles resembles the one created by the "local monopoly" of the pairwise meetings technology. ${ }^{8}$ Our results show that even allowing full transparency (removing fric-

\footnotetext{
${ }^{7}$ Our main qualitative results extend to the case of less extreme information structures, because the relevant incentive constraints are essentially the same.

${ }^{8}$ Note that the face-to-face restriction of the pairwise meetings trading technology can be approximated as the limit of the restrictions to market share of the model with clienteles as $n \rightarrow \infty$. Of course, technically, the cardinality of the continuum of buyers is larger than the limit of a sequence of a finite number of sellers, but the economic forces at work are well captured by this heuristic argument.
} 
tion (A) above), a model that retains an element of friction (B) alone, such as the clienteles, may yield that full revelation of information is not guaranteed. The results also suggest that while both the non-exclusivity of the information and intense competition among sellers encourage information revelation, the effect of the intensity of competition proves stronger than that of the non-exclusivity of information: with clienteles we always have equilibria with no information revelation, whether or not information is exclusive. These findings shed light on some of the reasons behind strategic information revelation, and contribute to our understanding of full revelation results as in REE. The reader may find the following diagram instructive, to appreciate how our models "fit between" the two paradigms that set out our discussion:

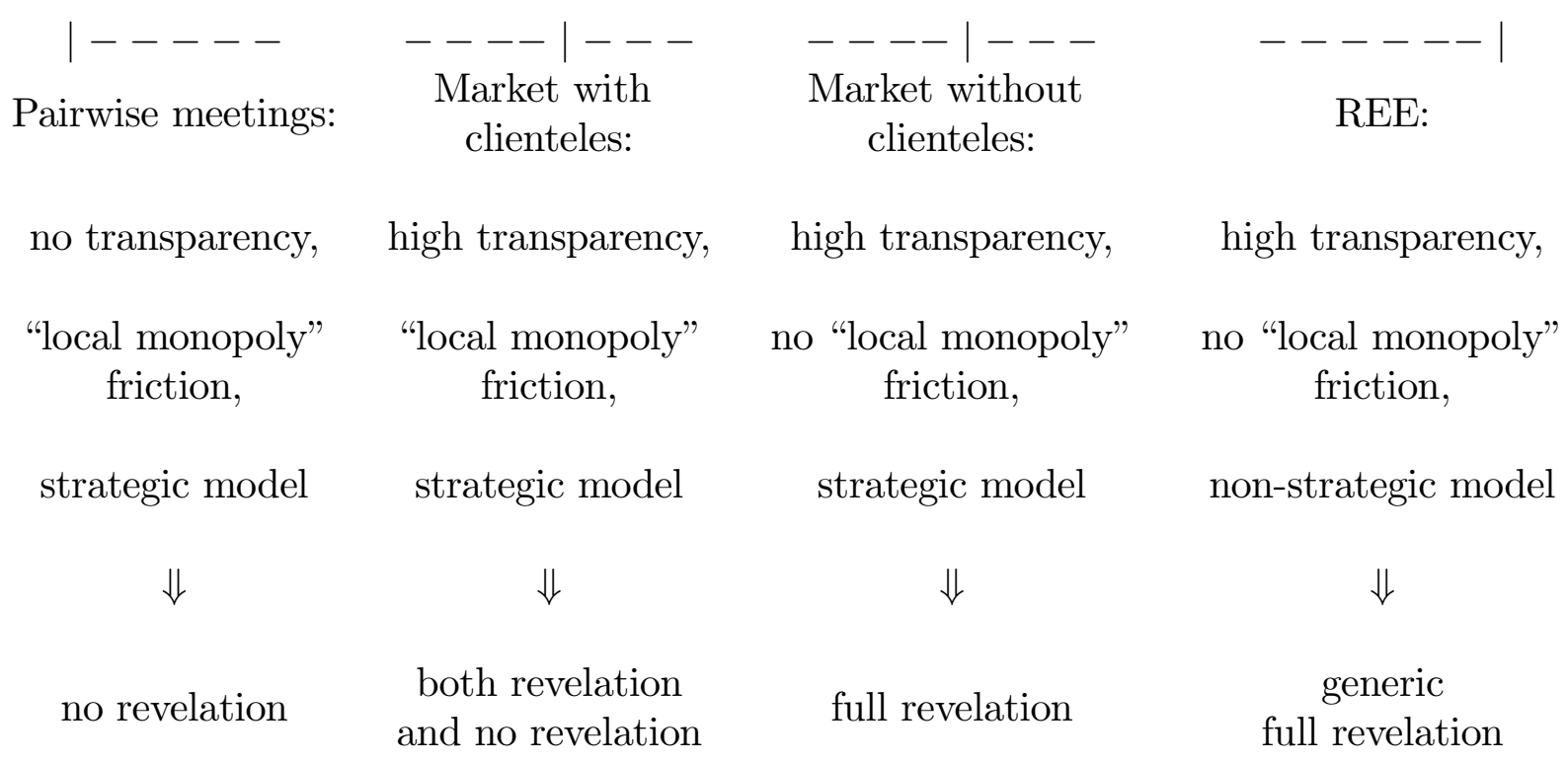

\section{The Model}

The economy. Agents are of two types: buyers and sellers. There are two commodities, an indivisible consumption good, initially owned by the sellers, and a perfectly divisible commodity ('money'), initially owned by the buyers. There is a continuum of buyers, whose measure is normalized to 1 . All buyers are identical: each of them is willing to buy at most one unit of the consumption good. There are $n$ sellers, $1 \leq n<\infty$, and each of them can sell an arbitrarily large number of units of the consumption good. Except possibly for their information, all sellers are also identical. 
Trade takes place over time and there is uncertainty over the quality of the indivisible good. Quality can be of two types, high $(H)$ or low $(L)$, and all units of the commodity in all periods are of the same quality. Uncertainty can thus be described by two aggregate states of the world, $H$ and $L$. The buyers' valuation for one unit of the commodity in the two states is, respectively, $u_{H}$ and $u_{L}$. Similarly, the sellers' unit reservation value is $c_{H}$ in state $H$ and $c_{L}$ in state $L$. Therefore, the valuation of the commodity is perfectly correlated across agents; we are in a situation of common values uncertainty. We assume that:

$$
u_{H}>c_{H}>u_{L}>c_{L} \geq 0 .
$$

Note that in each state there are positive gains from trade.

Let us denote by $\alpha_{0} \in(0,1)$ the prior belief, common to all agents in the economy, that the state of the world is $H$. In what follows, we will always assume that buyers are uninformed over the realization of the state of the world; hence their belief, when trading begins, is given by $\alpha_{0}$. On the other hand, we will allow for different cases with regard to the information held by sellers.

Trading rules. There are infinitely many trading dates. At each $t, t=1, \ldots$, each of the $n$ sellers simultaneously posts a price at which he is willing to sell the consumption good (to any number of buyers). After observing the $n$ quoted prices, each buyer chooses whether or not to trade in that period. If a buyer accepts an offer made in the period, he buys one unit at the proposed price and then exits the market (we shall specify from which seller he buys in the next paragraph). If the buyer rejects, he remains in the market and can then trade at some future date. Sellers remain in the market until all buyers are served, which may never happen. There are no new entrants in the market after the first period. The quality of the good becomes known to buyers only after they leave the market.

When there are several sellers $(n>1)$, we shall distinguish two possible forms of competition:

1. Model without clienteles. Each period $t$, following the announcement of the prices posted by the $n$ sellers, every buyer is free to trade with any of them. In this situation sellers compete in prices, under no capacity constraints; competition among sellers is then quite intense (as in the classical model of Bertrand competition).

2. Model with clienteles. Each period $t$, a fraction of size $1 / n$ of the buyers who are still in the market is randomly assigned to every seller. In that period each buyer can only buy from the seller he is assigned to. Since buyers 
observe all $n$ posted prices, and always have the option to refuse to trade, the temporary segmentation of the market introduced here does not eliminate price competition among sellers. It only mitigates its intensity, since undercutting prices has a less dramatic effect on the demand for each seller (resembling models of Cournot competition, or of Bertrand competition with capacity constraints). Also, information leakages from an informed seller to all uninformed traders are not prevented by the presence of clienteles.

Even though quite stylized, to fix ideas one can think of the model as portraying situations like a specific wine crop sold in a fair by the producers, or the market of derivatives on aggregate credit risk. In both situations we can argue all units sold are of the same quality, buyers and sellers are clearly identified, and there are reasons for trade other than differences in information. More generally, one may view informational asymmetries in financial markets as being typically over common values uncertainty (e.g., over the asset returns). One can then think of clienteles as buyers being inside the kiosk of a wine seller. In a given moment, they can buy only from that seller, although information flows across kiosks.

Both buyers and sellers evaluate payoffs from future trades according to the common discount factor $\delta \in(0,1)$. In this paper we are concerned with the limiting results as $n \rightarrow \infty$ rather than as $\delta \rightarrow 1$. However, all our results hold for any $\delta<1$ sufficiently large. We should think in fact of trading dates as taking place with a very high frequency; the reader is then invited to fix $\delta$ at some arbitrarily large value.

In most of the paper we focus our attention on the case where sellers can propose only one of two given prices, a high price $p_{H}, c_{H}<p_{H}<u_{H}$, and a low price $p_{L}, c_{L}<p_{L}<u_{L} .{ }^{9}$ Note that all the fully revealing REE of the static version of this economy would have a high price in state $H$ and a low price in state $L$ lying in the corresponding intervals above. In addition, this parsimonious formulation allows us to provide a complete characterization of all the equilibria of the trading game, and to better focus on the issues concerning information revelation we are primarily concerned with. In Appendix B we check for the robustness of our findings, by showing that most of the qualitative properties we derive for the equilibria remain valid also when sellers can choose from a continuum of prices.

Various cases with regard to the number of sellers in the economy and their information will be considered. This will allow us to disentangle in the revelation

\footnotetext{
${ }^{9}$ We consider strict inequalities to rule out non-robust indifferences.
} 
of information the role of market power given by the size of the sellers' market share from that given by their private information. In each case we characterize the perfect Bayesian equilibria of the trading game described above. From now on we refer to a perfect Bayesian equilibrium simply as an equilibrium.

As a benchmark case, we begin by analyzing the model with an informed monopolist in Section 3. In Section 4 we examine the oligopoly without clienteles and in Section 5 the one with clienteles. In both cases, we analyze the properties of the equilibria as the number of sellers gets large and perform our study under the following two extreme information structures. First, one where all sellers are informed. In this case, as $n$ grows, sellers are both "informationally small" and their market power as determined by their market share becomes negligible. Second, we analyze the polar opposite case: there are several sellers, but only one of them is informed (whose identity is common knowledge). Now, as $n$ gets large, this seller remains "informationally large", while his market share decreases (as that of all sellers), so that information is the only possible source of market power. The welfare properties of the equilibria are discussed in Section 6. Since the contribution of our paper lies in the comparison of results across models, not to interfere with the presentation all proofs are gathered in Appendix A.

\section{Monopoly}

Consider the case where there is only one seller $(n=1)$, who is fully informed of the realization of the uncertainty.

The following observations will allow us to simplify the definition of an equilibrium. Note first that when the seller observes state $H$ (i.e., the seller is of 'type $\left.H^{\prime}\right)$ he will always propose $p_{H}$ at any trading date. Also, whenever a buyer is proposed a price $p_{L}$ he will always accept, no matter what his belief is over the realization of the uncertainty.

On the other hand, the 'type $L$ ' seller faces a non-trivial choice between offering $p_{H}$ and $p_{L}$; similarly the buyers, when they are proposed $p_{H}$, have to decide whether to accept or reject. In both cases we will allow for the possibility that the agents may randomize in their choice. Let $q_{S}(t)$ denote the probability that the seller in state $L$ proposes $p_{H}$ at date $t$ (given histories according to which in all previous periods the seller always proposed $p_{H}$ and at least some buyers always rejected; similarly, let $q_{B}(t)$ be the probability that a typical buyer accepts, at date $t$, if the seller proposes $p_{H}$, given histories in which the seller always proposed $p_{H}$ 
in the past. ${ }^{10}$ The payoff of a buyer in a period where trade takes place, say at price $p_{H}$ in state $L$, is $u_{L}-p_{H}$; for the seller it is then $p_{H}-c_{L}$ times the fraction of buyers accepting.

Each period $t$, after observing the price proposed by the seller, buyers will also update their belief over the state of the world. If the seller proposes $p_{L}$ the buyers' inference is irrelevant since, as already argued, their optimal action is always to accept. Let $\alpha_{t}$ denote the buyers' belief at date $t$ that the state of the world is $H$ if the seller proposed $p_{H}$ at $t$ and in all past periods; such belief is updated every period, using Bayes' rule and taking into account the strategy of the type $L$ seller:

$$
\alpha_{t}=\frac{\alpha_{t-1}}{\alpha_{t-1}+\left(1-\alpha_{t-1}\right) q_{S}(t)} \text { for all } t \geqslant 1
$$

Note that $\alpha_{t}$ is always weakly increasing with $t$, and is strictly increasing as long as $q_{S}(t)<1$.

An equilibrium of the trading game with an informed monopolist is then described by the sequences $\left\{q_{B}(t)\right\}_{t \geq 1},\left\{q_{S}(t)\right\}_{t \geq 1},\left\{\alpha_{t}\right\}_{t \geq 1}$ such that:

(i) $\left\{\alpha_{t}\right\}_{t \geq 1}$ satisfies $(3.1)$;

(ii) at each $t$, after every partial history in which not all buyers accepted the seller's offer in one of the previous periods, $\left\{q_{B}(\tau)\right\}_{\tau>t}$ maximizes the buyers' discounted (to that date) payoff, given $\left\{q_{S}(\tau), \alpha_{\tau}\right\}_{\tau \geq t}$, and $\left\{q_{S}(\tau)\right\}_{\tau \geq t}$ maximizes the type $L$ seller's discounted payoff, given $\left\{q_{B}(\tau)\right\}_{\tau \geq t}$.

We will provide a complete characterization of the equilibria of this game. It will be shown that we never have complete revelation of the seller's information. In particular, if the prior belief $\alpha_{0}$ that the true state of the world is $H$ is sufficiently high, no information is ever revealed in the trading process: all equilibria exhibit perfect pooling (of the two seller's types) and no delay (all trades take place at the initial date). On the other hand, if the buyers' prior belief over $H$ is not high enough, some information gets always revealed in the first trading date (as, with

\footnotetext{
${ }^{10}$ Additional equilibria can be found in which all buyers play pure strategies, and a proportion $q_{B}(t)$ accepts the high price at date $t$, while the rest reject it. These equilibria are outcome equivalent to the ones we study. This is the sense in which there is no loss of generality in restricting attention to symmetric equilibria, as we shall do.
} 
some positive probability, the type $L$ seller will propose a revealing price, $\left.p_{L}\right)$. In this case, the monopolist will reveal the minimum amount of information needed to induce buyers to be willing to trade at a high price. After that is accomplished, no further information is ever revealed; we have so 'partial pooling'. In addition there is delay: while $p_{L}$ is always immediately accepted by buyers, when $p_{H}$ is proposed the buyers will reject, in all periods, with some positive probability. Delay can even be infinite.

Define $\bar{\alpha}$ to be such that $\bar{\alpha} u_{H}+(1-\bar{\alpha}) u_{L}=p_{H}$. That is, $\bar{\alpha}$ is the belief that makes buyers exactly indifferent between trading at $p_{H}$ with probability 1 and not trading at all. Formally, we have the following:

Proposition 1. In the model with an informed monopolist the following equilibria obtain:

(i) No information revelation: when $\alpha_{0} \geq \bar{\alpha}$, in any equilibrium, we have $q_{S}(t)=1$ for all $t$. In particular, if $\alpha_{0}>\bar{\alpha}$, the equilibrium is unique with $q_{B}(t)=1$ for every $t$. On the other hand, if $\alpha_{0}=\bar{\alpha}$, there are also equilibria where $q_{B}(t) \in(0,1]$ for all $t \geq 1$.

(ii) Partial and immediate revelation: when $\alpha_{0}<\bar{\alpha}$, in all equilibria, we have $q_{S}(1) \in(0,1)$ so that $\alpha_{1}=\bar{\alpha}, q_{S}(t)=1$ for all $t>1, q_{B}(t) \in(0,1]$ for all $t \geq 1$.

It is easy to see that the configurations we propose in the statement of Proposition 1 are indeed equilibria of the model. Most of the argument in the proof is devoted to show that no other behavior conforms with equilibrium. To gain some intuition on the result, notice that in our setup the profits a monopolist can get from his private information and his market power lie in the possibility of manipulating buyers' beliefs and induce buyers to agree to trade at a high price, with minimal delay. Our result shows that the seller will always succeed in generating such beliefs, by revealing the minimal amount of information (possibly zero) which is necessary, and all in the first period. There is however a cost, given by the fact that there may be (possibly considerable) delay in trade; the need for such cost comes from the fact that the seller is otherwise unwilling to choose to reveal part of his information in equilibrium.

\section{Oligopoly without Clienteles}

In this section we examine the case where there are $n>1$ sellers, who compete in prices among them, in the absence of clienteles. As described in Section 2, 
this means that each period sellers simultaneously announce a price in the set $\left\{p_{H}, p_{L}\right\}$, buyers get to observe the list of announced prices and the identity of the seller behind each price and can freely choose whom to trade with. Hence, if both prices are called on by sellers, those who announce $p_{L}$ split the entire market equally among them, while those announcing $p_{H}$ sell no units. In this situation, competition is quite fierce since each seller, by undercutting, can steal immediately its competitors' market share.

We will explore this model, as well as its counterpart with clienteles in the next section, under two extreme information structures: one in which all sellers are informed regarding the true state of the world and the other where only one of them is informed.

\subsection{All Informed Oligopolists}

As in the case of monopoly, state $H$ sellers will always charge $p_{H}$ and, as soon as the price $p_{L}$ is in the list of announced prices, all buyers remaining in the market will always buy at this price. If, on the other hand, all sellers announced $p_{H}$ in the first $t$ periods, the buyers' choice at $t$ depends on their belief $\alpha_{t}$ that the state of the world is $H$. Let $q_{B}(t)$ denote then the probability that a buyer accepts, at $t$, if all sellers propose $p_{H}$, given histories where all sellers offered $p_{H}$ in the past. The formal definition of the strategies of buyers and sellers - and hence of an equilibrium - is otherwise the same as in the previous section (we denote by $q_{S}(t)$ the probability that each state $L$ seller charges $p_{H}$ in period $t$ ); similarly, $\alpha_{t}$ is the buyers' belief at $t$ that the state is $H$ if all sellers proposed $p_{H}$ at $t$ and in each prior period. ${ }^{11}$

The non-exclusivity of the sellers' information, as well as the limits on their market power given by the presence of various sellers competing among them, impose severe constraints on their ability to hide their information and manipulate buyers' beliefs as in the case of monopoly. To hide the information would in fact require to repeatedly announce a high price even when the state is $L$. However, doing so now would give other sellers a strong incentive to undercut. Even though by undercutting the seller would reveal its information, the benefits from expanding its market share would be higher the larger is the number $n$ of sellers; hence, for $n$ sufficiently large they will outweigh the costs of revealing the information.

\footnotetext{
${ }^{11}$ Again we can restrict our attention, without loss of generality, to symmetric equilibria. The purification argument outlined above (in footnote 10) continues to apply to the buyers. Moreover, by the simple structure of the model, one can show that there are no asymmetric equilibria among sellers. Hence the notation $q_{S}(t)$ just presented.
} 
We proceed to characterize the equilibria of the model in this case. Due to the non-exclusivity of the information that each seller holds, there is always an equilibrium where all the information is immediately revealed: each seller in period 1 announces $p_{H}$ in state $H$ and $p_{L}$ in state $L$ with probability 1 , while buyers always accept both $p_{L}$ and $p_{H}$ (if all sellers offered $p_{H}$ ). When the number of sellers $n$ is small enough, we can also have 'collusive' equilibria, where sellers behave as in the equilibrium with monopoly obtained in the previous section, or where they randomize in state $L$ for the first $T$ periods and then always propose $p_{L}$. However, as $n$ grows, all these 'collusive' strategies cease to be part of equilibria, and there is no other equilibrium than full and immediate information revelation. Formally,

Proposition 2. In the model with $n$ informed sellers without clienteles:

(i) Full and immediate information revelation: for any $n \geqslant 2$, there always exists an equilibrium where $q_{S}(1)=0$ and $q_{B}(1)=1$.

(ii) For $n$ small enough, the following equilibria also exist:

(ii.a) No revelation or partial immediate revelation: all sellers (and hence buyers) behave as in the monopoly equilibrium.

(ii.b) Full revelation but with delay: $q_{S}(t) \in(0,1)$ and $q_{B}(t) \in(0,1)$ for $1 \leq t<T$, and $q_{S}(t)=0, q_{B}(t)=1$ for $\left.t \geq T\right)$.

(iii) Asymptotically, full and immediate revelation in all equilibria: for $n$ sufficiently large all the equilibria in (ii) vanish and the unique equilibrium is the one described in (i).

\subsection{One Informed Oligopolist}

We explore now a different information structure, in which there is only one informed seller, whose identity is commonly known and whose information is then exclusive. $^{12}$ As a consequence, the informed seller has the same ability as the monopolist to hide his information. However, to be able to profit from this in the presence of other (uninformed) sellers, the informed seller must be able to successfully manipulate both the buyers' and the other sellers' beliefs to induce all of them to trade at a high price, and this may not always be possible, as we will see. This is not optimal, when the number of sellers in the market is sufficiently

\footnotetext{
${ }^{12}$ If the identity of the informed seller were not known, the inferences of the uninformed traders from the observation of the proposals made would be more difficult; however, one can show that the validity of our results extends to that case, due to the strong (resp. weak) undercutting incentives in the absence (presence) of clienteles.
} 
large: in that case in fact the incentives to undercut and steal all his competitors' market share prove too strong, even though by so doing all information would be revealed.

More specifically, for $n$ small, we have equilibria where no information is revealed (and there may even be no equilibrium with full revelation): the informed seller hides his information, partially or completely, and with some positive probability trade takes place at $p_{H}$ in both states. However, for $n$ sufficiently large, the equilibrium is unique and reveals immediately the information to the buyers, as in the case where all sellers are equally informed.

Combining the results of both subsections it becomes apparent that the large number of sellers competing in the market under the absence of clienteles, but not the differences in the information structure, seems to be the key feature to allow information to be fully and immediately revealed to the consumers.

To characterize the equilibria formally, we need now to describe separately both the strategy of the informed seller, in states $H$ and $L$, and the uninformed sellers (and buyers). As before, the informed seller in state $H$ will always charge $p_{H}$. We denote then by $q_{I}(t)$ and $q_{U}(t)$ the probability that the state $L$ informed seller and each uninformed seller, respectively, charge $p_{H}$ at date $t$. Let $q_{B}(t)$ be the probability that buyers accept $p_{H}$ in period $t$, following a history where the only price announced by sellers has been $p_{H}$.

Some further notation is also needed to identify the relevant cutoff values in the beliefs of uninformed sellers. Let:

$\widetilde{\alpha}$ be the belief that makes uninformed sellers indifferent between trading at $p_{L}$ and not trading at all: $\widetilde{\alpha}\left(p_{L}-c_{H}\right)+(1-\widetilde{\alpha})\left(p_{L}-c_{L}\right)=0$. Thus for $\alpha<\widetilde{\alpha}$ an uninformed seller strictly prefers trade at $p_{L}$ to no trade.

$\hat{\alpha}$ be the belief that makes uninformed sellers indifferent between not trading at all and announcing $p_{L}$, when every other uninformed seller proposes $p_{H}$ while the informed state $L$ seller proposes $p_{L}: \hat{\alpha}\left(p_{L}-c_{H}\right)+(1-\hat{\alpha}) \frac{p_{L}-c_{L}}{2}=0$. For $\alpha>\hat{\alpha}$ no uninformed seller would offer $p_{L}$ in this situation.

It can be easily verified that $\widetilde{\alpha}>\hat{\alpha}$.

Proposition 3. In the model with $n$ sellers, only one of whom is informed, without clienteles:

(i) For $n$ large enough, there is always an equilibrium with full and immediate 
information revelation. Specifically,

(i.a) Full information revelation to all uninformed traders: for large enough $n$ and for all $\alpha_{0} \geqslant \hat{\alpha}$, there exists an equilibrium where $q_{U}(1)=1, q_{I}(1)=0$ and $q_{B}(1)=1$ (that is, at $t=1$ the uninformed sellers charge $p_{H}$, the informed seller charges $p_{H}$ in state $H$ and $p_{L}$ in state $L$, and buyers accept both $p_{L}$ and $p_{H}$, provided all sellers offered $p_{H}$ ).

(i.b) Full information revelation to buyers: for large enough $n$ and for all $\alpha_{0}<\widetilde{\alpha}$, there exists an equilibrium where $q_{U}(1)=q_{I}(1)=q_{B}(1)=0$ (at $t=1$ the uninformed sellers charge $p_{L}$, the informed seller charges $p_{H}$ in state $H$ and $p_{L}$ in state $L$, and buyers accept only $p_{L}$ at $t=1$ ).

(ii) No full revelation: for $n$ sufficiently small there are equilibria where $q_{I}(t), q_{U}(t) \in$ $(0,1]$ and $q_{B}(t) \in(0,1]$ for all $t \leq T$, for some finite $T \geq 1$.

(iii) Asymptotically, full and immediate revelation in all equilibria: as $n \rightarrow \infty$, the only equilibria are the ones in (i).

The uninformed sellers' behavior also depends on their beliefs about the state. However, as in the monopoly section, in the situation considered here there is still no need to specify off-equilibrium path beliefs after unilateral deviations (of the informed seller). The inference both of buyers and uninformed sellers is in fact irrelevant when the informed seller (or, for that matter, any seller) announces $p_{L}$ since the optimal response of buyers is always to accept in this case and hence the game ends immediately. On the other hand, there is no off-equilibrium deviation to $p_{H} \cdot 13$

In this model information is monopolized by one seller. However, Proposition 3 makes it clear that, as $n$ grows large, the intensity of price competition among sellers in the model with no clienteles gives too strong an incentive to undercut and hence all information is revealed to the buyers right away. The equilibrium in (i.b), that also survives for all $n$, is characterized by the fact that all information is immediately revealed to the buyers, but there is no revelation to the uninformed sellers, who end up trading at $p_{L}$ in state $H$. Their prior belief giving low probability to the state being high leads them to bear a payoff in that state that is not ex post individually rational.

\footnotetext{
${ }^{13}$ With regard to deviations by uninformed sellers, when $n>2$ there will always be at least one uninformed offering $p_{L}$, thus leading to an immediate termination of the game.
} 


\section{Oligopoly with Clienteles}

We analyze here to what extent the results obtained in the previous section (in particular, the fact that all information, whether exclusive or not, is immediately revealed to the buyers when there are sufficiently many sellers) remain valid when less extreme forms of price competition are considered. To this end, as anticipated in Section 2, we introduce the model with clienteles, whose main difference from the previous one is that each period a buyer can only buy from his designated seller; hence the term clientele. This association only lasts one period, as each time $t$ the buyers remaining in the market are randomly reassigned to sellers. By undercutting, each seller can now steal only a limited fraction of his competitors' market share.

Again we proceed to study the model when there are $n$ sellers under the two extreme information structures.

\subsection{All Informed Oligopolists}

If all other informed sellers choose $p_{L}$, i.e., to reveal their information, and this is commonly observed by all buyers, the best reply of a seller is clearly to do the same, as long as there is some, even very weak, competition among sellers. Thus full and immediate revelation of the information remains an equilibrium in the model with clienteles, because of the non-exclusivity of information.

On the other hand, as already mentioned, the gains from undercutting are now much more limited. To see this more precisely, consider the situation where, at some date $t$ in state $L$ all sellers announce $p_{H}$. We can construct now different equilibria supporting this outcome using different off-equilibrium beliefs when one seller deviates to $p_{L}$. If these beliefs are that the state is $L$ with probability 1 , buyers will reject all offers of $p_{H}$. Thus only the seller who announced $p_{L}$ will sell to the $1 / n-t h$ of the market constituting his clientele for the period. The remaining $(n-1) / n-t h$ of the buyers on the market at $t$ will then still be around at $t+1$ and will be equally split among the $n$ sellers. At $t+1$ all sellers will offer $p_{L}$ if the buyers' strategy is to keep rejecting all offers of $p_{H}$. Thus by undercutting, an informed seller can only increase his market share from $\frac{1}{n}-t h$ to $\frac{1+(n-1) / n}{n}-t h$ of the market; moreover, his increase in market share will take one period to materialize. As a consequence, collusive behavior among sellers, and in particular to hide the information and profitably manipulate buyers' beliefs, is now easier. This shows that if the collusive payoff in state $L,\left(p_{H}-c_{L}\right)$, is tempting enough, the "local monopoly" power created by the presence of clienteles suffices for the 
existence of another (collusive) equilibrium regardless of the number of sellers: each seller behaves as in the monopoly equilibrium and no information, or only the minimal amount necessary to trade at the high price, is revealed. Furthermore, with other off-equilibrium beliefs, there is a collusive equilibrium that does not necessitate the assumption of the collusive payoff being large enough. We give its details in part (ii) of the next proposition.

This stands in clear contrast with our findings for the model without clienteles. It reveals that, even in the absence of exclusivity of information, no revelation may occur at equilibrium, whatever the number of sellers, when the intensity of competition among sellers is not too strong. It also shows that the nature of competition among sellers appears to play a more important role than the exclusivity of information in determining whether or not information is fully revealed to the buyers, when there are many sellers.

Formally, we have: ${ }^{14}$

Proposition 4. In the model with $n$ informed sellers with clienteles:

(i) Full and immediate information revelation: for all $n \geq 2$ and all $\alpha_{0}$ there is always an equilibrium where $q_{S}(1)=0$ and buyers accept $p_{H}$ in period 1 when all prices announced in that period are $p_{H}$.

ii) For any $n \geq 2$, the following collusive equilibria (where sellers behave as in the case of monopoly) also exist:

(ii.a) No revelation: when $\alpha_{0} \geqslant \bar{\alpha}, q_{S}(t)=1$ for all $t$ and buyers immediately accept $p_{H}$;

(ii.b) Partial revelation: when $\alpha_{0}<\bar{\alpha}$ and

$$
p_{H}-c_{L} \geqslant\left(p_{L}-c_{L}\right)\left[\delta+\frac{\left(1-\alpha_{0}\right) \bar{\alpha}}{\alpha_{0}(1-\bar{\alpha})}\right]
$$

$q_{S}(1) \in(0,1)$ so that $\alpha_{1} \geq \bar{\alpha}$ and buyers accept with probability 1 if all sellers announce $p_{H}$; for $t>1$ we have $q_{S}(t)=1$ and all buyers accept $p_{H}$.

\subsection{One Informed Oligopolist}

As we saw in the previous subsection, in the presence of clienteles hiding the information can be profitable for an informed seller, whatever the number of sellers (this is true in particular when the profits per unit sold at a high price are

\footnotetext{
${ }^{14}$ We use here again $q_{S}(t)$ to denote the probability that a seller proposes $p_{H}$ in state $L$ at date $t$.
} 
sufficiently higher than the profits from a sale at a low price). However, with nonexclusive information a fully revealing equilibrium always exists, together with collusive equilibria, for any $n$. When there is only one informed seller, information is exclusive and the informed seller can always hide it, as in the case of monopoly. We should expect then that in this situation full revelation is difficult to achieve. Indeed, we will show that, for many parameter configurations, separation is impossible at equilibrium and an equilibrium exists where at least part of the information is never revealed. The only case in which hiding the information can prove too costly for the informed seller is when both the gain in the per unit profit obtained by selling at $p_{H}$ in state $L$ is sufficiently low and the prior belief of the uninformed sellers sufficiently optimistic so that they may be willing to offer a low price.

The results are again in clear contrast with what we found in the model without clienteles. If information is exclusive, we should not expect it to be revealed at equilibrium, when the intensity of the competition among sellers is not too strong.

Proposition 5. In the model with $n$ sellers, only one of whom is informed, and with clienteles:

(i.a) Full revelation is impossible for many parameter configurations: for any $n \geq 2$, if $p_{H}-c_{L}>\left(p_{L}-c_{L}\right)(1+\delta)$ (the collusive payoff is not too small), or $\alpha_{0}<\left(p_{L}-c_{L}\right) /\left(c_{H}-c_{L}\right)$ for all $t$ (beliefs are sufficiently pessimistic), at equilibrium we have $q_{I}(t)>0$ for all $t$;

(i.b) Full revelation only occurs for some parameter values: there exists $n$ large enough such that, for $p_{H}-c_{L}<\left(p_{L}-c_{L}\right)(1+\delta)$ and $\alpha_{0}>\left(p_{L}-c_{L}\right) /\left(c_{H}-c_{L}\right)$, there is an equilibrium with $q_{I}(1)=0$.

(ii) For any $n \geq 2$, the following additional equilibria exist:

(ii.a) No revelation: when $\alpha_{0} \geq \bar{\alpha}, q_{U}(t)=q_{I}(t)=1$ for all $t$ (both the uninformed sellers and the informed seller in both states charge $\left.p_{H}\right)$ and buyers immediately accept;

(ii.b) Partial revelation: when $\alpha_{0}<\bar{\alpha}$ and $\left(p_{H}-c_{L}\right)>\left(p_{L}-c_{L}\right)(1+\delta)$, $q_{I}(1) \in(0,1)$ and $q_{U}(1)=1$ (the informed seller randomizes in state $L$ in the initial period, while the uninformed charge $\left.p_{H}\right)$; for all $t>1$ we have $q_{I}(t)=q_{U}(t)=1$. In every period, buyers randomize between accepting and rejecting when all announced prices are $p_{H}$.

Thus, for a large subset of the parameter region full separation never occurs and only collusive equilibria exist, whatever the number of sellers $n$. For the 
complementary region, separation can be supported, but collusive equilibria are also found. Thus, the message of the model with clienteles is somewhere between the information revelation findings -and hence convergence to fully revealing REE - of the model without clienteles, where competition is quite intense, and the nonrevelation results of the pairwise meetings literature, where the local monopoly power of each seller in every meeting is reinforced by the lack of observability of public signals that could help reveal the information.

\section{Welfare Analysis}

We discuss here the welfare properties of the equilibria we obtained. As known from the literature on REE, equilibria with full and immediate information revelation are ex post Pareto efficient. In our set-up, where all traders are risk neutral, such equilibria are also interim efficient, and characterized by no delay in trading. ${ }^{15}$

An important issue is then whether a result of lack of information revelation implies simply a transfer of welfare from the uninformed to the informed agents or rather, whether it is an instance of inefficiencies, manifesting themselves for example with delay in trading. In evaluating such efficiency properties we should take into account the fact that information is private, and hence require improvements to satisfy incentive compatibility conditions (i.e., evaluate allocations according to the notion of interim incentive efficiency). As shown in Serrano and Yosha (1996) and Blouin and Serrano (2001), information revelation was always accompanied by efficiency in the pairwise meetings models, while no-revelation caused interim inefficiencies due to delay in learning. The same conclusion (i.e., that revelation obtains if and only if there are negligible welfare losses) does not emerge in the present paper. For brevity, we will simply state the results and not provide the details of the arguments, which are available upon request.

\subsection{Monopoly}

(i) The equilibria with perfect pooling and immediate acceptance by the buyers, obtained when $\alpha_{0} \geq \bar{\alpha}$, are clearly interim efficient: all gains from trade are exhausted, with no delay.

\footnotetext{
${ }^{15}$ Interim efficiency refers to the case where agents' welfare is evaluated conditionally on their information at the initial date, prior to the opening of markets.
} 
(ii) On the other hand, the equilibria with delay (obtained when $\alpha_{0} \leq \bar{\alpha}$ ) are always interim incentive inefficient.

Thus, the equilibrium with no information revelation in (i) translates in a welfare transfer to the informed monopolist (with respect to the case of full information revelation), without entailing any welfare loss. On the other hand, the partial revelation of the information occurring at the equilibrium in (ii) creates delay and imposes a net loss in total welfare. We can show in fact that an (incentive compatible) improvement can be found in this case if buyers' behavior is kept the same as at this equilibrium, while the seller charges $p_{L}$ with probability 1 in state $L$ : such mechanism leaves the welfare of the two types of the seller unchanged (with respect to the equilibrium outcome), but strictly improves buyers, and is incentive compatible. Moreover, such inefficiency persists even with arbitrarily small discounting, when we let $\delta \rightarrow 1$, so that the cost of delaying trade by any finite number of periods become vanishingly small: this is due to the fact that, as $\delta$ approaches 1 , a significant fraction of trades takes place with longer and longer, possibly infinite, delay.

Although the comparison among the equilibrium payoffs of buyers and sellers in the equilibria of type (i) and (ii) (without and with delay) involves agents in different economies, characterized by different values of the prior belief $\alpha_{0}$, it is worth noting that both types of the seller have a strictly lower payoff in the second equilibrium than in the first. Thus, information revelation comes at a cost to the seller.

\subsection{Oligopoly without Clienteles}

When all sellers are informed we found that the only equilibrium that survives for any number of sellers $n$ is the one with full and immediate information revelation which, as we argued, is not only ex post but also interim Pareto efficient. When compared to the pooling equilibrium obtained under monopoly, the sum of the payoffs of sellers in state $L$ is now lower while buyers' payoffs are higher. This transfer to buyers is the cost to the sellers of information revelation, but unlike the monopolist case, information revelation here does not destroy society's welfare.

When only one seller is informed, two types of equilibria exist for all $n$. Both are separating equilibria and the information, privately held by the only informed seller, is fully revealed to the buyers.

(i) In the equilibrium described in part (i.a) of Proposition 3, the informed seller in state $H$ shares the market with the uninformed sellers, while in 
state $L$ he manages to appropriate the entire market. Each buyer continues to receive the same expected payoff as when all sellers are informed. This equilibrium is also interim efficient and the total payoff of sellers and buyers is the same as with all sellers informed. The only difference one should stress is the transfer of surplus from the uninformed sellers to the informed seller in state $L$. Again, information revelation is achieved without any welfare loss.

(ii) While the equilibrium described in part (i.b) of Proposition 3 is also interim efficient because of the absence of delay in trading, its features are somewhat distinct. In this equilibrium the more optimistic beliefs of the uninformed traders crowd out the informed seller in state $H$, who sells nothing. The informed seller in state $L$ now shares the market with the uninformed sellers, who on the other hand sell in both states. Buyers are of course the clear winners, paying a low price in both states and avoiding delays. Recall that even though this equilibrium is interim efficient, information is not revealed to the uninformed sellers: all trade occurs at $p_{L}$ in state $H$ so that uninformed sellers, driven by their optimistic beliefs, end up transacting at a price that is not ex post individually rational (in $H$ ).

\subsection{Oligopoly with Clienteles}

With regard to the case of all informed sellers, one possible equilibrium outcome (Proposition 4, part (i)) is again full and immediate information revelation, as in Proposition 2. The other, collusive equilibria obtained in Proposition 4 are very close to the ones found in Proposition 1 for the case of the monopolist. The reader is referred to the previous subsections for discussions of their welfare properties.

Consider next the equilibria with only one informed seller. When separation is sustained in equilibrium all trade takes place at $p_{L}$ in state $L$ and at $p_{H}$ in state $H$. The welfare properties of this equilibrium are similar to the ones of the separating equilibrium described in (ia) of Proposition 3, with two differences: (i) there is delay, though this should now be viewed as a trade friction generated by the presence of clienteles; (ii) the distribution between uninformed and informed sellers of their profits in state $L$ is now more equal.

In contrast, at the equilibria where the informed hides his information, the total payoff of buyers and sellers is the same as at the equilibria obtained under monopoly. In some of these equilibria, delay occurs due to the buyers' randomization and this causes inefficiencies. Note also that the expected payoff for the 
informed and uninformed sellers is the same in this case (unlike in the equilibria of the model without clienteles); thus the existence of clienteles exerts a positive externality on the uninformed sellers and, clearly a negative externality on buyers, who pay the high price in both states.

\section{Related Literature}

As mentioned in the introduction, other papers examine the strategic foundations of REE, considering some specific trading mechanisms. Dubey, Geanakoplos and Shubik (1987) and more recently Forges and Minelli (1997) study the case where trading takes place via market games a la Shapley and Shubik (1977), in the presence of a continuum of agents of finitely many types. Each source of information is possessed by a continuum of agents. They show that, when the trading game is repeated, the Nash equilibria are such that the first stage is used to exchange information among traders (equilibrium prices act as public signals), and in the subsequent stages the outcome coincides, under appropriate conditions, with the fully revealing REE. The case of a market game where strategy sets are demand functions is analyzed by Kyle (1989) with finitely-many informed traders: he shows the existence of equilibria where only part of the information is revealed and studies how the amount of information revelation varies with the share of informed traders relative to both uninformed and noise traders.

In a static auction context, Pesendorfer and Swinkels (1997) and Perry and Reny (2003) study conditions under which sequences of symmetric equilibria aggregate information and converge to REE. Closer to our work, Peters and Severinov (2002) study the issue in a sequential auction context, in which traders' observations of the actions of others allow them to make inferences about the true state.

The case in which there is a single informed trader acting strategically is considered by Grinblatt and Ross (1985), Laffont and Maskin (1990) within a oneperiod model, and by Kyle (1985) in a dynamic setting. In both cases it was shown that the monopolist may choose not to completely reveal his private information and that equilibria differ from REE. To understand the differences with respect to our results, in particular in the case of Kyle's work, note that he considers a model with noise traders, where prices are determined each period by competitive market-makers on the basis of the observation of aggregate trades. Thus, aggregate trades, and a fortiori prices, cannot fully reveal the private information of the informed trader. Even if he were to act non strategically, full revelation could 
only be achieved in the limit, after infinitely many rounds of trade. Since he acts strategically, convergence of prices to their full information value is slower since the informed agent is able to "hide" his trades from the market. Our result for the monopolist case is different, because continued randomization, whereby information is progressively revealed over time, is never optimal, due to discounting and the absence of noise traders.

Information revelation is also addressed in models of dynamic trading with more than a single informed trader by various papers extending the analysis of Kyle (1985). Vives (1995) examines a situation with a large number of risk averse informed traders acting myopically, finding that convergence is rather fast (see however Medrano and Vives (2001), where the addition of a large strategic agent to the set-up of Vives (1995) limits information revelation). Several informed traders are introduced in the dynamic trading model of Kyle (1985) by Holden and Subrahmanyan (1992); they show, via numerical simulations of the model, that strategic agents compete aggressively by sending very large trade orders, thereby neutralizing the effect of noise traders and leading to quick revelation (in line with our findings for the case in which all sellers are informed). Such results however no longer hold if the signals received by informed traders are only imperfectly correlated, as shown by Foster and Viswanathan (1996) (also via numerical simulations); again there are some analogies with our findings for the case of only one informed seller, in the model without clienteles.

The difficulties met in establishing the convergence of the equilibria of strategic models to competitive outcomes with asymmetric information over common value uncertainty should be contrasted with the case of complete information, or even of asymmetric information of the private values type. In these cases perfect competition arises as a fairly robust limit of game theoretic models when the number of traders increases (see, e.g., Rustichini, Satterthwaite and Williams (1994), Satterthwaite and Williams (2002) and Cripps and Swinkels (2004) in a double auction context). Note that this occurs even in models of random matching and pairwise meetings (see Gale (1987), Serrano (2002), Shneyerov and Satterthwaite (2003)). We should also point out that in a dynamic set-up market power may vanish even in the case of monopoly: the Coase conjecture for a durable goods monopolist, uninformed about the demand curve he faces, shows in fact that monopoly pricing, under reasonable assumptions, converges to the competitive price as the frequency of trades increases (see, for example, Gul, Sonnenschein and Wilson (1986)).

Finally, even though formally ours is not a repeated game, we should also 
mention the relationship between our work (particularly in the case of a single informed seller) and the literature on two-player repeated games with incomplete information, where partial revelation results in which information is revealed in the first stages are also obtained. See Forges (1992), Zamir (1992), Mertens, Sorin and Zamir (1994) and references therein.

\section{Appendix A: Proofs}

This appendix contains the proofs of our results.

\section{Proof of Proposition 1:}

The proof proceeds by establishing first some properties of the equilibria:

A) Full and immediate information revelation never occurs (in finite time); at no date the seller in state $L$ proposes $p_{L}$ with probability 1 . Formally:

Lemma 1. At any equilibrium, $q_{S}(t)>0$ for every $t$.

Proof of Lemma 1: Suppose not: there exists a period $t$ such that $q_{S}(t)=0$. Since, if the state is $H$, the seller proposes $p_{H}$ for certain, it follows that there is full separation at $t$. Thus we have $\alpha_{t}=1$. Upon observing $p_{H}$ at $t$ the buyers can infer the state is $H$ for certain and so their optimal strategy must always be to accept $p_{H}$ with probability 1 at date $t\left(q_{B}(t)=1\right)$. But then the optimal strategy of the seller in state $L$ at $t$ would be to propose $p_{H}$ rather than $p_{L}$, a contradiction.

B) If at some $t$ the buyers' strategy is to accept $p_{H}$ for sure, then in that period the type $L$ seller will propose $p_{H}$ for certain. This in turn implies, when the buyers' belief $\alpha_{t}$ is sufficiently close to 1 , that at each earlier date the buyers should also prefer to accept $p_{H}$ for sure; hence the seller must prefer to propose $p_{H}$ for certain. Hence we have:

Lemma 2. If, at an equilibrium, $q_{B}(t)=1$ for some $t$, then we must also have $q_{S}(t)=1$. If, in addition, $\alpha_{t}>\bar{\alpha}$ we obtain that, for every $t^{\prime}<t, q_{B}\left(t^{\prime}\right)=q_{S}\left(t^{\prime}\right)=$ 1. 
Proof of Lemma 2: This is easily established by backwards induction. If in period $t, q_{B}(t)=1$, the seller's best response in that period is clearly $q_{S}(t)=1$. Since $q_{S}(t)=1, \alpha_{t-1}=\alpha_{t}$; thus, if $\alpha_{t}>\bar{\alpha}$ the buyers' payoff from accepting at $t-1$ is positive and strictly higher than the payoff from accepting at $t$, for all $\delta<1$. The buyers' best response in period $t-1$ must then be $q_{B}(t-1)=1$. Iterating the argument, we find that the same must be true at all previous dates $t^{\prime}<t$.

C) If in equilibrium buyers randomize for infinitely many periods, their belief $\alpha_{t}$ must jump to a sufficiently high level at the initial date and stay constant at that level forever after:

Lemma 3. If, at every date $t, q_{B}(t) \in(0,1)$, then we must have $\alpha_{t}=\bar{\alpha}$ for all $t$.

Proof of Lemma 3: Note that the evolution of posterior beliefs $\alpha_{t}$ is determined from Bayes' rule using the seller's strategy and, accordingly, follows equation (3.1). As we already noticed, this sequence of posterior beliefs is non-decreasing in $t$. In addition, to sustain the buyers' randomization in every period, we need the following condition to hold at all $t:^{16}$

$$
\begin{aligned}
& \alpha_{t} u_{H}+\left(1-\alpha_{t}\right) u_{L}-p_{H}=\delta\left[\left(1-\alpha_{t}\right)\left(1-q_{S}(t+1)\right)\left(u_{L}-p_{L}\right)+\right. \\
& \left.+\left(1-\left(1-\alpha_{t}\right)\left(1-q_{S}(t+1)\right)\right)\left(\alpha_{t+1} u_{H}+\left(1-\alpha_{t+1}\right) u_{L}-p_{H}\right)\right]
\end{aligned}
$$

where on the left hand side we have the payoff from accepting $p_{H}$ and, on the right hand side, the payoff from rejecting it at $t$ and accepting it at $t+1$.

Because by hypothesis, the randomization involves infinitely many periods, the infinite sequence of posteriors $\left\{\alpha_{t}\right\}$, which is monotone and bounded, has a limit. We will show that $\lim _{t \rightarrow \infty} \alpha_{t}=\bar{\alpha}$.

Suppose $1>\lim _{t \rightarrow \infty} \alpha_{t}>\bar{\alpha}$; in this case, by equation $(3.1), \lim _{t \rightarrow \infty} q_{S}(t)=1$. But if we consider (7.1) and take the limit as $t \rightarrow \infty$, plugging $\lim _{t \rightarrow \infty} q_{S}(t)=1$ in and using the fact that $\lim _{t \rightarrow \infty}\left(\alpha_{t}-\alpha_{t+1}\right)=0$, we reach a contradiction, because for $\delta<1$ the term on the right hand side of (7.1) will be strictly lower than the one on the left hand side, so buyers strictly prefer to accept.

Similarly, if $\lim _{t \rightarrow \infty} \alpha_{t}=1$ : the term on the left of (7.1) tends to $u_{H}-p_{H}$ while the term on the right tends to $\delta\left(u_{H}-p_{H}\right)$, which is strictly lower, thus again we get a contradiction.

\footnotetext{
${ }^{16}$ The same arguments apply if the randomization does not involve two consecutive periods. The right hand side of (7.1) is then more involved, but the essence of the argument is identical.
} 
It remains then to show that we cannot have $\lim _{t \rightarrow \infty} \alpha_{t}<\bar{\alpha}$ either. But this is immediate, since the expected payoff from accepting a $p_{H}$ offer, $p_{H}-\alpha_{t} u_{H}+(1-$ $\left.\alpha_{t}\right) u_{L}$, is negative whenever $\alpha_{t}<\bar{\alpha}$. Thus buyers would be better off by refusing to trade altogether at $t$, instead of randomizing between accepting and rejecting.

Finally, note that, in order to sustain the randomization of the buyers at any date $t$, it must be $\alpha_{t} \geqslant \bar{\alpha}$. This fact, together with the property $\lim _{t \rightarrow \infty} \alpha_{t}=\bar{\alpha}$ established above, implies that infinite randomization of the buyers requires $\alpha_{t}=$ $\bar{\alpha}$ for all $t$.

We are now ready to establish the claim of the Proposition. By Lemma 1, pure strategies where $q_{S}(t)=0$ for some $t$ can never be part of an equilibrium. Consider then the only other possible pure strategy of the type $L$ seller, $q_{S}(t)=1$ for all $t$.

If $\alpha_{0} \geq \bar{\alpha}$, a best reply for the buyers to this strategy is $q_{B}(t)=1$ for all $t$ : their expected payoff is in fact non-negative and any other strategy would only induce delay and still result in either no trade or trade at the same price, $p_{H}$, yielding so a lower (weakly if $\alpha_{0}=\bar{\alpha}$ ) payoff. The strategy $q_{S}(t)=1$ for all $t$ is then also the seller's best reply to $q_{B}(t)=1$ for all $t$ since the payoff obtained by the type $L$ seller is $p_{H}-c_{L}$, the highest possible. This establishes that $q_{B}(t)=q_{S}(t)=1$ for all $t$ is an equilibrium if $\alpha_{0} \geq \bar{\alpha}$, as claimed in part (i) of the statement of the proposition.

On the other hand, if $\alpha_{0}<\bar{\alpha}$, the buyers' best reply to $q_{S}(t)=1$ for all $t$ is $q_{B}(t)=0$ for all $t$; but then the seller's best reply is $q_{S}(t)=0$ for all $t$, so that we do not have a pure strategy equilibrium in this case.

Consider next the candidate equilibria where buyers randomize for infinitely many periods. From Lemma 3, such equilibria require the seller to - possibly randomize at the initial date, so as to induce the posterior belief $\alpha_{1}=\bar{\alpha}$, and to propose $p_{H}$ with probability 1 at all later dates $t>1$. This is clearly possible only if $\alpha_{0} \leq \bar{\alpha}$ (hence, when $\alpha_{0}>\bar{\alpha}$ these equilibria never exist).

Let us denote by $V_{L}(t)$ the present value, at $t$, of the discounted expected flow of payoffs of the type $L$ seller, given that he always proposed $p_{H}$ in the past (including the current period $t$ ), and got always rejected; $V_{L}(t)$ satisfies then the following:

$$
V_{L}(t)=q_{B}(t)\left(p_{H}-c_{L}\right)+\delta\left(1-q_{B}(t)\right) V_{L}(t+1)
$$

Any sequence of values $q_{B}(t) \in(0,1)$ satisfying the conditions: 


$$
\begin{aligned}
& p_{L}-c_{L}=q_{B}(1)\left(p_{H}-c_{L}\right)+\delta\left(1-q_{B}(1)\right) V_{L}(2) \\
& p_{L}-c_{L} \leq q_{B}(t)\left(p_{H}-c_{L}\right)+\delta\left(1-q_{B}(t)\right) V_{L}(t+1) \text { for all } t>1
\end{aligned}
$$

supports the strategy $q_{S}(1) \in(0,1), q_{S}(t)=1$ for all $t>1$ as the seller's best response to $\left\{q_{B}(t)\right\}_{t}$. It is immediate to verify that we can always find some, in fact many, sequences with this property. Furthermore, since $\alpha_{t}=\bar{\alpha}$ for all $t \geqslant 1$, any sequence of values $q_{B}(t) \in(0,1)$ is a best reply for the buyers. Thus, as stated in part (ii) of the statement of the proposition, such equilibria always exist if $\alpha_{0}<\bar{\alpha}$. By a similar argument, any sequence of values $q_{B}(t) \in(0,1)$ satisfying the inequality in the second equation of (7.3) for all $t \geq 1$ and the seller's strategy $q_{S}(t)=1$ for all $t \geq 1$ are a best response to each other (and hence constitute an equilibrium) when $\alpha_{0}=\bar{\alpha}$.

To complete the proof of the Proposition, it remains to consider the possibility of an equilibrium where buyers randomize for a positive but finite number of periods. ${ }^{17}$ Suppose that there is an equilibrium where $q_{B}(t)=0$ for all $t$ greater or equal than some date $T \geqslant 2$. Then the seller's best response, as we already argued, would be $q_{S}(t)=0$ for all $t \geqslant T$, which by Lemma 1 cannot be part of an equilibrium.

On the other hand, if $q_{B}(t)=1$ for all $t \geqslant T \geqslant 2$ is part of an equilibrium strategy, we must have $\alpha_{T} \geqslant \bar{\alpha}$. If $\alpha_{T}>\bar{\alpha}$ we reach again a contradiction, by Lemma 2. If $\alpha_{T}=\bar{\alpha}$ and $\alpha_{t}<\bar{\alpha}$ for $t<T$, we must have $q_{S}(T) \in(0,1)$; for this choice of the seller to be optimal we need, from (7.3), taking into account that $q_{B}(T)=1$, the following equality to hold, $p_{L}-c_{L}=p_{H}-c_{L}$, which is impossible. We are then left with the case where $\alpha_{T}=\bar{\alpha}$ and, for some $\bar{t}<T, \alpha_{t}=\bar{\alpha}$ for $\bar{t}<t<T$, so that $q_{S}(t)=1$ for all $t>\bar{t}, q_{S}(\bar{t}) \in(0,1)$. Note first that this can only be part of an equilibrium if $\bar{t}=1$ and hence $\alpha_{t}=\bar{\alpha}$ for all $t \geq 1$. $^{18}$ The conditions for the optimality of the seller's strategy are again given by (7.3), where $V_{L}(2)$ is defined recursively by (7.2) together with the equality $V_{L}(T-1)=p_{H}-c_{L}$. It is easy to check that, for any $\delta<1$ we can find $T$, sufficiently high, such that these conditions are satisfied for some sequence $\left\{q_{B}(t)\right\}_{t>1}$ exhibiting the property $q_{B}(t)=1$ for all $t \geqslant T$. The closer is $\delta$ to 1 , the larger is the minimal number of periods of randomization $T$ required.

\footnotetext{
${ }^{17}$ It is immediate to see that we can only have an equilibrium where buyers never randomize if the seller also never randomizes, the case already considered at the beginning of the proof.

${ }^{18}$ If $\bar{t}>1$, so that $\alpha_{t}<\bar{\alpha}$ and hence $q_{B}(t)=0$ for $t<\bar{t}$, from the inequality in the second equation of $(7.3)$ we obtain $p_{L}-c_{L} \leq \delta V_{L}(t+1)$ for $t<\bar{t}$. But this is impossible since $q_{S}(\bar{t}) \in(0,1)$ implies that $V_{L}(\bar{t})=p_{L}-c_{L}$.
} 
We conclude that, when $\alpha_{0} \leq \bar{\alpha}$, there exist equilibria where buyers randomize both for an infinite and a finite number $T$ of periods, with $T$ larger the closer is $\delta$ to 1. On the other hand, if $\alpha_{0}>\bar{\alpha}$, there are no equilibria where buyers randomize.

Proof of Proposition 2:

Claim (i) follows immediately from the non-exclusivity of each seller's information. Effectively, if a seller anticipates that his competitors offer price $p_{L}$ in state $L$ (i.e. choose to fully reveal their information), the unique best response for him is to do the same. The alternative is in fact losing entirely his market share.

Consider next the seller's strategy in the monopoly equilibrium (ii.a). The best possible deviation for a seller, when every other seller follows this strategy, is to announce $p_{L}$ at a node where the strategy prescribes to offer $p_{H}$ with probability 1. If the seller undercuts and offers $p_{L}$, he sells to the whole market at the price $p_{L}$, so that his profits (starting from that node) are $p_{L}-c_{L}$. On the other hand, the profits obtained by adhering to the collusive strategy are $\frac{p_{H}-c_{L}}{n}$ (i.e. the seller's share of the monopoly profits). ${ }^{19}$ Hence, the choice of the monopoly strategy for all sellers remains optimal if and only if $\frac{p_{H}-c_{L}}{n} \geq p_{L}-c_{L}$, which holds for small enough $n$; this proves claim (ii.a).

Turning to (ii.b), the optimality of the prescribed strategy for sellers require them to be indifferent, in each of the first $T$ periods, between offering $p_{H}$ or $p_{L}$. In particular, for $t=T$, we must have:

$$
q_{S}^{n-1}(T)\left[q_{B}(T) \frac{p_{H}-c_{L}}{n}+\left(1-q_{B}(T)\right) \delta \frac{p_{L}-c_{L}}{n}\right]=q_{S}^{n-1}(T)\left(p_{L}-c_{L}\right)+R(T),
$$

where on the left hand side is the payoff from offering $p_{H}$ (at $T$ ), on the right hand side the payoff from $p_{L}$ and $R(T)$ denotes the expected payoff to charging $p_{L}$ in the event that some of the competitors also charge $p_{L}$. Since $R(T) \geq 0$, when $n$ is sufficiently large (7.4) cannot hold, no matter what are $q_{S}(T), q_{B}(T) \in[0,1]$, thus showing that even this strategy cannot be part of an equilibrium. On the other hand, for $n$ small (but greater than 2) we may be able to find $q_{S}(t), q_{B}(t) \in[0,1]$ satisfying (7.4) and the analogous equalities for $t=1, . ., T-1$, thus showing that temporary collusion may be an equilibrium in that case.

To complete the proof of the Proposition, we have to show that no other equilibrium exists. Claims (i) and (ii.a) characterize the equilibria where sellers follow pure strategies or randomize for finitely many periods and switch then to

\footnotetext{
${ }^{19}$ Strictly speaking, in the special case where $\alpha_{0}=\bar{\alpha}$ the profits are less or equal this level.
} 
$p_{H}$; claim (ii.b) describes the possible equilibria where sellers randomize for finitely many periods and then switch to $p_{L}$. It remains to consider the case where sellers in state $L$ randomize for infinitely many periods. By a similar argument to the monopoly case we can show:

Lemma 4. There is no equilibrium where the sellers in state $L$ randomize for infinitely many periods.

Proof of Lemma 4: Note that for sellers to randomize at any period $t\left(0<q_{S}(t)<\right.$ 1 ), buyers have to accept $p_{H}$ with positive probability: $q_{B}(t)>0$. Moreover, for the game not to end with probability 1 in finite time, it must be $q_{B}(t)<1$ for all $t$, i.e. buyers have also to randomize for infinitely many periods. Recall then Lemma 3: this result is still valid and implies that $\lim _{t \rightarrow \infty} \alpha_{t}=\bar{\alpha}$. But, if sellers randomize during infinitely-many periods, the sequence $\left\{\alpha_{t}\right\}_{t \geqslant 1}$ is strictly increasing so that, for any $t$, we have $\alpha_{t}<\bar{\alpha}$, which contradicts the fact that $q_{B}(t)>0$.

This completes the proof of the Proposition.

Proof of Proposition 3:

(i.a) Given the strategies for the other players described in the statement of (i.a), when $\alpha_{0} \geqslant \hat{\alpha}$ the expected profit for an uninformed seller from offering $p_{L}$ is non-positive. Hence in this situation an optimal choice for any uninformed seller is indeed to offer $p_{H}$, which yields a positive expected profit, $\frac{1}{n}\left(p_{H}-c_{H}\right) \alpha_{0}$. The informed seller in state $L$ then strictly prefers to charge price $p_{L}$ if:

$$
p_{L}-c_{L}>\frac{1}{n}\left(p_{H}-c_{L}\right)
$$

always satisfied for $n$ sufficiently high.

(i.b) When the other uninformed sellers, as well as the informed one in state $L$, offer $p_{L}$, an uninformed seller also prefers to charge $p_{L}$ if:

$$
\alpha_{0}\left(p_{L}-c_{H}\right) \frac{1}{n-1}+\left(1-\alpha_{0}\right)\left(p_{L}-c_{L}\right) \frac{1}{n} \geq 0 .
$$

If $\alpha_{0}<\tilde{\alpha}$ this inequality is always satisfied for $n$ large enough. It is then immediate to see that the informed seller's choice of offering $p_{L}$ (in state $L$ ) is an optimal response to the uninformed's strategy, since $\frac{p_{L}-c_{L}}{n} \geq 0$. 
(ii) Let $n$ be sufficiently small so that $p_{L}-c_{L} \leq \frac{1}{n}\left(p_{H}-c_{L}\right)$. Note that $p_{L}-c_{L} \geq$ $\left(p_{L}-c_{H}\right) \alpha_{0}+\left(1-\alpha_{0}\right)\left(p_{L}-c_{L}\right)$ for all $\alpha_{0}$; the unit expected payoff of trading at $p_{L}$ is always higher for the informed than for the uninformed seller since the first one can choose to trade at this price only in state $L$.

First, we have equilibria that resemble the ones found in the monopoly section. That is, if $\alpha_{0} \geq \bar{\alpha}$, offering $p_{H}$ every period both for the uninformed sellers and the informed seller in the $H$ and $L$ states constitutes an equilibrium. ${ }^{20}$

In addition, there are equilibria that involve randomization on the part of the informed seller in state $L$ for $T>1$ periods: in period $T+1$, the informed seller in state $L$ must charge $p_{L}$ (this low price in the final trading date is needed to sustain the randomization of buyers, which in turn is required for the informed seller to be willing to randomize). In the first $T$ periods, in some of these equilibria the uninformed sellers charge $p_{H}$ while in others they randomize between $p_{H}$ and $p_{L}$; in period $T+1$ they will charge $p_{L}$ (if $\alpha_{T+1}<\widetilde{\alpha}$ ) or randomize.

(iii) We show finally that as $n \rightarrow \infty$ the only equilibria are those with full and immediate separation described in (i). Evidently, there is no equilibrium where the informed seller in state $L$ charges $p_{H}$ with probability 1 (as the first of the equilibria described in (ii)): with $n$ large undercutting is always preferred. By an argument similar to the one in the proof of Lemma 4, sellers cannot randomize for infinite periods. We are left then with examining the other equilibria described in (ii), where the type $L$ seller randomizes for $T$ periods before choosing $p_{L}$ with probability 1.

Suppose first that the uninformed sellers choose $p_{H}$ at $T+1$. Then, the indifference condition for the informed seller in period $T$ between $p_{L}$ and $p_{H}$ is:

$$
\begin{aligned}
& q_{U}^{n-1}(T)\left(p_{L}-c_{L}\right)+\sum_{r=1}^{n-1}\left(1-q_{U}(T)\right)^{r} q_{U}^{n-1-r}(T) \frac{(n-1) !}{r !(n-1-r) !} \frac{p_{L}-c_{L}}{r+1}= \\
& q_{U}^{n-1}(T)\left[\frac{p_{H}-c_{L}}{n} q_{B}(T)+\delta\left(p_{L}-c_{L}\right)\right] .
\end{aligned}
$$

For $n$ sufficiently large, the term on the right hand side is approximately $q_{U}^{n-1}(T) \delta\left(p_{L}-\right.$ $\left.c_{L}\right)$. This is smaller than the first term on the left hand side because $\delta<1$, and in addition, the rest of terms on the left hand side are not negligible. Thus, the expression on the left hand side exceeds the one on the right hand side, which is a contradiction.

The same is true, a fortiori, if the uninformed choose $p_{L}$ with positive probability at $T+1$. So we conclude that these also cease to be equilibria for $n$ large.

\footnotetext{
${ }^{20}$ If, on the other hand $\alpha_{0}<\bar{\alpha}$, there is an equilibrium where the informed seller in state $L$ randomizes in the initial period to induce the belief $\alpha_{1}=\bar{\alpha}$.
} 
Proof of Proposition 4:

(i) We omit this proof, as it is similar to that of claim (i) of Proposition 2.

(ii.a) When the strategy of the buyers is to accept $p_{H}$ if all sellers propose $p_{H}$, and that of all the other sellers is to propose $p_{H}$ in state $L$ at date 1 , the profit for a seller if he does the same (offer $p_{H}$ ) is $\frac{p_{H}-c_{L}}{n}$. On the other hand, if he were to undercut and charge $p_{L}$, he would sell immediately to the $\frac{1}{n}$ share of buyers constituting his clientele at $t=1$. Assigning off-equilibrium path beliefs after this deviation equal to the beliefs on the equilibrium path and assuming that the sellers' strategy is still to offer $p_{H}$ at any later date (i.e., the same equilibrium behavior as in period 1), buyers will continue to accept all offers of $p_{H}$ at $t=1$. The payoff for undercutting is then only $\frac{p_{L}-c_{L}}{n}$, so that charging $p_{H}$ is clearly the sellers' best response. ${ }^{21}$ Given the sellers' strategy, since $\alpha_{0} \geqslant \bar{\alpha}$, all buyers then prefer to immediately accept both $p_{L}$ and $p_{H}$.

(ii.b) Taking as given the strategies of the buyers and the other sellers as described in part (ii.b) of the statement, the payoff to a seller in period 1 in the event that $r>0$ sellers other than himself announce $p_{L}$ is:

$$
\delta\left(p_{L}-c_{L}\right) \frac{n-r}{n^{2}}
$$

if he charges $p_{H}$, and

$$
\frac{p_{L}-c_{L}}{n}+\delta\left(p_{L}-c_{L}\right) \frac{n-1-r}{n^{2}}
$$

if he charges $p_{L}$. The probability of this event is then $\left(q_{S}(1)\right)^{n-1-r}\left(1-q_{S}(1)\right)^{r} \frac{(n-1) !}{(r !(n-1-r) !)}$.

On the other hand, if $r=0$ sellers other than him charge $p_{L}$, his payoff is

$$
\frac{p_{H}-c_{L}}{n}
$$

if he charges $p_{H}$,

$$
\frac{p_{L}-c_{L}}{n}+\delta\left(p_{L}-c_{L}\right) \frac{n-1}{n^{2}}
$$

if he charges $p_{L}$ and the probability of this event is $\left(q_{S}(1)\right)^{n-1}$.

To sustain indifference, we need that the expected payoff of $p_{H}$ equals the expected payoff of $p_{L}$, i.e. that the sum of the above terms describing the payoff

\footnotetext{
${ }^{21}$ On the other hand, when the off-equilibrium path beliefs following a deviation to $p_{L}$ are such that the probability of $L$ is 1 (as discussed earlier, in the second paragraph of section 5.1), the same conclusion holds under the condition $p_{H}-c_{L} \geqslant\left(p_{L}-c_{L}\right)(1+\delta)$.
} 
associated to $p_{H}$, weighted by their respective probabilities, over all $r$ running between 0 and $n-1$, equals the sum of the corresponding terms describing the payoff associated to $p_{L}$. Noting that, for all $r>0$ the difference between (7.5) and (7.6) equals $\frac{p_{L}-c_{L}}{n}\left[\frac{\delta}{n}-1\right]$, simplifying terms we obtain the following equality:

$$
\left(1-\left(q_{S}(1)\right)^{n-1}\right) \frac{p_{L}-c_{L}}{n}\left[\frac{\delta}{n}-1\right]+\left(q_{S}(1)\right)^{n-1} \frac{1}{n}\left[\left(p_{H}-c_{L}\right)-\left(p_{L}-c_{L}\right)\left(1+\delta \frac{n-1}{n}\right)\right]=0,
$$

which can be simplified to:

$$
\frac{p_{L}-c_{L}}{n}\left[\frac{\delta}{n}-1-\left(q_{S}(1)\right)^{n-1} \delta\right]+\frac{p_{H}-c_{L}}{n}\left(q_{S}(1)\right)^{n-1}=0 .
$$

Next, let $\bar{q}_{S}$ be the value of $q_{S}(1)$ that generates an updated belief of the buyers, after observing all sellers announcing $p_{H}$, of $\alpha_{1}=\bar{\alpha}$ :

$$
\bar{q}_{S}^{n}=\frac{\alpha_{0}(1-\bar{\alpha})}{\left(1-\alpha_{0}\right) \bar{\alpha}} .
$$

Observe that $q_{S}(1)$ can be set to take any value between $\bar{q}_{S}$ and 0 , thus inducing a belief $\alpha_{1} \geq \bar{\alpha}$, and hence supporting the buyers' choice to immediately accept both $p_{H}$ and $p_{L}$. When $q_{S}(1)=0$, the term on the left hand side of (7.7) is clearly negative. On the other hand, when $q_{S}(1)$ is such that $q_{S}(1)=\bar{q}_{S}$, the sign of this term is equal to the sign of:

$$
\left(p_{H}-c_{L}\right)\left(\frac{\alpha_{0}(1-\bar{\alpha})}{\left(1-\alpha_{0}\right) \bar{\alpha}}\right)^{(n-1) / n}+\left(p_{L}-c_{L}\right)\left[\frac{\delta}{n}-1-\left(\frac{\alpha_{0}(1-\bar{\alpha})}{\left(1-\alpha_{0}\right) \bar{\alpha}}\right)^{(n-1) / n} \delta\right]
$$

which is positive, for all $n$, under the condition in the statement of part (ii.b). ${ }^{22}$ Therefore, it is always possible to find a value of $q_{S}(1) \in\left[0, \bar{q}_{S}\right]$ so that (7.7) is satisfied.

\section{Proof of Proposition 5:}

(i.a) Suppose full separation occurs in equilibrium in some period $t$. Then, the state $H$ informed seller charges $p_{H}$ in that period, and the state $L$ informed seller

\footnotetext{
${ }^{22}$ The term on the left hand side of $(7.8)$ is positive if $\left(p_{H}-c_{L}\right)>\left(p_{L}-c_{L}\right)[\delta+(1-$ $\left.\left.\frac{\delta}{n}\right)\left(\frac{\left(1-\alpha_{0}\right) \bar{\alpha}}{\alpha_{0}(1-\bar{\alpha})}\right)^{(n-1) / n} \delta\right]$. Noting that $\left(\frac{\left(1-\alpha_{0}\right) \bar{\alpha}}{\alpha_{0}(1-\bar{\alpha})}\right)$ is the reciprocal of a probability, and hence is greater than 1 , we have $\left(\frac{\left(1-\alpha_{0}\right) \bar{\alpha}}{\alpha_{0}(1-\bar{\alpha})}\right)>\left(\frac{\left(1-\alpha_{0}\right) \bar{\alpha}}{\alpha_{0}(1-\bar{\alpha})}\right)^{(n-1) / n}$ so that the condition in the statement of (ii.b) can be used in the above inequality to get the result.
} 
charges $p_{L}$. By Bayes' rule, the buyers and the uninformed sellers must update their beliefs at $t$ to $\alpha_{t}=1$, upon observing the informed seller charging $p_{H}$, and to $\alpha_{t}=0$ upon observing the informed seller charging $p_{L}$. If $p_{L}$ is observed, the clientele of the informed seller must clearly accept. But so must the clientele of the informed seller if he charges $p_{H}$, because the only reason to reject would be to expect $p_{L}$ in the future. However, the low price in the future could only come from the uninformed sellers, who believe now that the state is $H$ with probability 1 , and hence will never charge the low price. Therefore, the clientele of the informed seller must accept both $p_{H}$ and $p_{L}$. It follows that in state $H$ all units are sold in period $t$ because all buyers accept even $p_{H}$. When all the uninformed announce $p_{L}$ (which may only occur when $\alpha_{0} \leq \alpha_{t}<\left(p_{L}-c_{L}\right) /\left(c_{H}-c_{L}\right)$ ), the informed seller's profits from announcing $p_{L}$ in state $L$ are then $\frac{p_{L}-c_{L}}{n}$, always smaller than the profits from announcing $p_{H}$, given by $\frac{p_{H}-c_{L}}{n}$. On the other hand, when all the uninformed announce $p_{H}$, the informed's profits from announcing $p_{L}$ in state $L$ are $\frac{p_{L}-c_{L}}{n}+\delta\left(p_{L}-c_{L}\right) \frac{n-1}{n^{2}}$, again smaller than the profits from announcing $p_{H}\left(\frac{p_{H}-c_{L}}{n}\right)$ under the conditions stated in (i.a). Thus, under those conditions the informed seller in state $L$ has an incentive to deviate and charge $p_{H}$.

(i.b) The strategies supporting separation are as follows. The informed seller charges $p_{L}$ in state $L$ and $p_{H}$ in state $H$ in every period. The uninformed sellers also charge $p_{H}$ in period 1 , but switch to $p_{L}$ if they observe the informed seller charging $p_{L}$. Buyers accept both prices if they observe the informed seller charging $p_{H}$. They accept only $p_{L}$ if they observe the informed seller charging $p_{L}$.

The optimality of the buyers' strategy easily follows from the degeneracy of their beliefs (obtained by using Bayes' rule at all information nodes where the informed charge $p_{H}$ or $p_{L}$, thus assigning off-equilibrium beliefs when only uninformed sellers deviate equal to the ones on the equilibrium path). Considering next the informed seller in state $L$, given that the collusive payoff is not too attractive (the first condition on the parameter values imposed in (i.b)), there exists $n$ large enough such that $p_{L}$ is a best response:

$$
\frac{p_{L}-c_{L}}{n}+\delta\left(p_{L}-c_{L}\right) \frac{n-1}{n^{2}}>\frac{p_{H}-c_{L}}{n} .
$$

Finally, the uninformed sellers prefer to charge $p_{H}$ at $t=1$ if

$\alpha_{0} \frac{p_{H}-c_{H}}{n}+\delta\left(1-\alpha_{0}\right) \frac{\left(p_{L}-c_{L}\right)(n-1)}{n^{2}}>\alpha_{0} \frac{p_{L}-c_{H}}{n}+\left(1-\alpha_{0}\right)\left(p_{L}-c_{L}\right)\left(\frac{1}{n}+\frac{\delta(n-2)}{n^{2}}\right)$,

which simplifies to:

$$
\alpha_{0}\left(p_{H}-p_{L}\right)>\left(1-\alpha_{0}\right)\left(p_{L}-c_{L}\right)(1-\delta / n) .
$$


The validity of this condition is ensured by the assumption made on $\alpha_{0}$ in (i.b) for large enough $n$.

(ii.a) We construct here an equilibrium where $p_{H}$ is announced by all sellers in period 1. Therefore, the belief held by uninformed traders is equal to their prior $\alpha_{0}$. Because $\alpha_{0} \geq \bar{\alpha}$, buyers are at a best response accepting $p_{H}$. Furthermore, we consider the case where the off-equilibrium belief, following a deviation to $p_{L}$ in period 1, remains $\alpha_{0}$; hence $p_{H}$ continues to be accepted by buyers. In this situation, charging $p_{H}$ is clearly the best response for the informed seller in state $L$ as the effect of charging $p_{L}$ would be to lower the profits from $\frac{p_{H}-c_{L}}{n}$ to $\frac{p_{L}-c_{L}}{n}$ (because of the clientele friction, given the assigned off-equilibrium beliefs, undercutting would only have the effect of lowering revenues over the same market share. $)^{23}$

By essentially he same argument, charging $p_{H}$ is also a best response for any uninformed seller. If he were to deviate to charging $p_{L}$, the beliefs held by uninformed traders are unchanged and hence buyers continue to accept $p_{H}$ from all the other sellers. Thus his expected profits would be $\alpha_{0} \frac{p_{L}-c_{H}}{n}+\left(1-\alpha_{0}\right) \frac{p_{L}-c_{L}}{n}$, lower than the ones obtained by charging $p_{H}$, given by $\alpha_{0} \frac{p_{H}-c_{H}}{n}+\left(1-\alpha_{0}\right) \frac{p_{H}-c_{L}}{n}$.

(ii.b) Let $q_{B}$ be the probability with which buyers accept $p_{H}$, in any period $t$, when all prices announced (at $t$ and any earlier date) are $p_{H}$. By Bayes' rule, upon observing $p_{L}$ charged by the informed seller and $p_{H}$ by all uninformed, the posterior belief is that the state is $L$ with probability 1 .

We begin by analyzing the incentives of the informed seller in state $L$. For him to be willing to randomize in period 1 the following equality must hold:

$$
\frac{p_{L}-c_{L}}{n}\left[1+\delta \frac{n-1}{n}\right]=\frac{p_{H}-c_{L}}{n}\left[q_{B}+\frac{\delta\left(1-q_{B}\right) q_{B}}{1-\delta\left(1-q_{B}\right)}\right]
$$

Under the condition we imposed that the collusion payoff is attractive enough, it is easy to see that, for fixed $\delta$ and $n$, there exists a unique value of $q_{B}$ that makes the equality hold. This will be the equilibrium value of $q_{B}$. At any later date $t>1$ the payoff from announcing $p_{H}$ and $p_{L}$ are again the same (when the off-equilibrium beliefs, following a deviation to $p_{L}$, are that the state is $L$ with probability 1 ); hence charging $p_{H}$ is (weakly) a best response.

Consider next the uninformed sellers. If one of them deviates to $p_{L}$ we assign

\footnotetext{
${ }^{23}$ As in Proposition 4, when the off-equilibrium path beliefs following a deviation to $p_{L}$ are, on the other hand, such that the probability of $L$ is 1 , a limited increase in the seller's market share is obtained if he undercuts. The deviation is again non profitable under the condition $p_{H}-c_{L} \geqslant\left(p_{L}-c_{L}\right)(1+\delta)$.
} 
off-equilibrium beliefs equal to the ones on the equilibrium path. Clearly the payoff associated to this deviation is only positive provided $p_{L}>\alpha_{0} c_{H}+(1-$ $\left.\alpha_{0}\right) c_{L}$. In that case, if the strategy of all traders following this deviation prescribes offering $p_{L}$, it is easily verified that the expected payoff for deviating to $p_{L}$ is $\frac{p_{L}-\left(\alpha_{0} c_{H}+\left(1-\alpha_{0}\right) c_{L}\right)}{n}\left[1+\delta \frac{n-1}{n}\right]$. This expression, taking into account (7.9), is strictly smaller than the expected payoff from $p_{H}, \frac{p_{H}-\left(\alpha_{0} c_{H}+\left(1-\alpha_{0}\right) c_{L}\right)}{n}\left[q_{B}+\frac{\delta\left(1-q_{B}\right) q_{B}}{1-\delta\left(1-q_{B}\right)}\right]$. This shows that the deviation considered is unprofitable.

Note, finally, that the probability that the informed seller charges $p_{H}$ at $t=1$ is chosen so as to yield $\alpha_{1}=\bar{\alpha}$. Thus, buyers are willing to randomize at $t=1$ between accepting and rejecting upon the observation of all prices being $p_{H}$. Given that pooling on $p_{H}$ takes place from period 2 on, buyers are best-responding by continuing their randomization in any period $t>1$.

\section{Appendix B: Robustness of Results}

The results obtained on the characterization of the equilibria are robust to the extension of the model along several dimensions. We will formally establish the properties for the monopoly model and discuss then the extension to the oligopoly case.

\section{Continuum of prices:}

The characterization of the equilibria was obtained under the simplifying assumption that the seller can only propose one of two possible prices, $p_{H}$ and $p_{L}$, exogenously given. We show here that the main qualitative properties of equilibria, in particular with regard to their information and efficiency properties, remain essentially the same when the seller is free to propose any price in a closed interval, subset of $\left(c_{L}, u_{H}\right)$. Thus, for the issues we have studied, our simplifying assumption is without essential loss of generality.

a) We still have no equilibrium sequence with separation in finite time, i.e., the seller charging different prices at some $t$ in $H$ and $L$ with probability $1 .{ }^{24}$ The result follows by a straightforward extension of Lemma 1 in Appendix A. Suppose such an equilibrium existed. In state $H$ the seller would offer a

\footnotetext{
${ }^{24}$ This stands in contrast with the result in Laffont and Maskin (1990) who show that a separating equilibrium always exists, in the setup of a one period trading model where the uninformed's demand is strictly decreasing in the price.
} 
price $\bar{p} \geq c_{H}$ (sales at any price below $c_{H}$ would in fact result in losses). If buyers accept such price for sure, the seller in state $L$ would prefer to also charge $\bar{p}$, rather than the separating price, which is some price $p$ less or equal than $u_{L}$, a contradiction. But there are no equilibria either where the high price is always rejected with some positive probability: such randomization on the part of buyers requires in fact, after period $t$ (when information is revealed), a decreasing sequence of prices in state $H$, which at some point would have to fall below $c_{H}$, again a contradiction. ${ }^{25}$

b) If the prior belief $\alpha_{0}$ is high enough, so that we can find prices (typically an interval $I \subseteq\left[c_{H}, u_{H}\right)$ ) at which both types of the seller as well as buyers are willing to trade, pooling equilibria with immediate trading again exist, though now there is a continuum of them.

For any $p \in I$, there is in fact an equilibrium where the seller charges $p$ both in state $H$ and $L$ and buyers accept; if the seller deviates to $p^{\prime} \neq$ $p$, off-equilibrium beliefs are such that $\alpha_{1}=0$, thus buyers accept $p^{\prime}$ if and only if $p^{\prime} \leq u_{L}$, which ensures that no profitable deviation exists for any type of seller. Having this continuum of equilibria, the complicated issue of equilibrium coordination arises, which we avoid with our simplifying assumption.

c) If $\alpha_{0}$ is small enough so that there is no price at which buyers and the seller in both states are willing to trade, the seller's strategy in state $L$ needs to be such that some information is revealed, as in the case considered before with only two prices.

Therefore, equilibria are always characterized by the fact that the state $L$ seller randomizes in the initial period between two prices. The low price is always given by $u_{L}$. (To see this, note that following such a low price announcement we have a complete information game between the state $L$ seller and the buyers. In such a game, $u_{L}$ is the only equilibrium price.) The high price is some price above $c_{H}$, that is also charged by the seller in state $H .{ }^{26}$ Buyers randomize then between accepting and rejecting.

\footnotetext{
${ }^{25}$ Note that if $u_{H}$ were allowed as a possible price an equilibrium of this type would exist: set $\bar{p}=u_{H}, p=u_{L}$, and $q_{B}(t)$ constant and low enough to deter deviations of the state $L$ seller.

${ }^{26}$ It is possible that the seller randomizes in state $H$ too (and the state $L$ seller randomizes over the low price and more than one level of the high price). The argument in the text easily extends to this case.
} 
c1) We always have equilibria where, at all subsequent dates $t>1$, the state $L$ seller no longer randomizes and proposes the high price, while buyers keep randomizing between accepting and rejecting.

Such equilibria have then the same features as the equilibrium with partial information revelation we obtained in the previous section for the case of low $\alpha_{0}$. Again there is a continuum of such equilibria, for the different values that the high price can take.

c2) There may be additional equilibria, where the seller (in state $L$ ) randomizes for an arbitrary, possibly infinite, number of periods.

At all equilibria where the state $L$ seller randomizes for more than one period (so that $\alpha_{t+1}>\alpha_{t} \geqslant \bar{\alpha}$ ) buyers have to randomize and, by essentially the same argument as in the proof of Lemma 2, they have to do it at all periods. This will in turn be optimal provided the following condition holds:

$\alpha_{t} u_{H}+\left(1-\alpha_{t}\right) u_{L}-p_{H}(t)=\delta\left(1-\left(1-\alpha_{t}\right)\left(1-q_{S}(t+1)\right)\right)\left(\alpha_{t+1} u_{H}+\left(1-\alpha_{t+1}\right) u_{L}-p_{H}(t+1)\right)$,

where $p_{H}(t)$ denotes the price charged by the seller in state $H$ with probability 1 and in state $L$ with probability $q_{S}(t)$, which may now vary with $t$. Since the sequence of posterior beliefs $\left\{\alpha_{t}\right\}_{t \geqslant 1}$ must converge and the prices in state $H,\left\{p_{H}(t)\right\}_{t \geqslant 1}$, cannot fall below $c_{H}$, as $t$ tends to infinity, condition (7.10) can only hold if, for large $t$, we have

$$
\alpha_{t} u_{H}+\left(1-\alpha_{t}\right) u_{L}-p_{H}(t) \cong \alpha_{t+1} u_{H}+\left(1-\alpha_{t+1}\right) u_{L}-p_{H}(t+1) \cong 0
$$

Note that $\alpha_{t} u_{H}+\left(1-\alpha_{t}\right) u_{L}-p_{H}(t) \geqslant 0$ for all $t$ and (7.10) implies that the sequence $\left\{\alpha_{t} u_{H}+\left(1-\alpha_{t}\right) u_{L}-p_{H}(t)\right\}_{t}$ is increasing; hence from (7.11) we get:

$$
\alpha_{t} u_{H}+\left(1-\alpha_{t}\right) u_{L}-p_{H}(t)=0 \text { for all } t,
$$

i.e., buyers are always indifferent between trading and not trading at $p_{H}(t)$, as in the equilibrium with one period randomization we found above in c1). Moreover, from $(7.12)$ it follows that the price $p_{H}(t)$ proposed in state $H$ increases over time.

Thus we can have information being revealed now over many periods. However, it is important to notice that, as shown below, at all such equilibria the payoffs of buyers and the seller are either equal or lower to the ones obtained in the equilibria where the seller in state $L$ randomizes for only one period. The equilibria 
with more periods of information revelation (as in c2) are then interim Pareto dominated by the equilibrium with only one period of randomization (as in c1). More information revelation requires greater delays in trading and hence entails a welfare loss.

Lemma 5. At all equilibria where the state $L$ seller randomizes for more than one period (as in c2), the payoff of buyers and the state $L$ seller is the same while the payoff of the state $H$ seller is lower than in an equilibrium where the state $L$ seller randomizes for one period only (as in c1).

Proof of Lemma 5. From the above description it is immediate to see that the present value of the discounted expected flow of payoffs at an equilibrium as in c2) is $u_{L}-c_{L}$ for the seller in state $L$ and 0 for buyers (since, as we argued, $p_{L}=u_{L}$ ), thus for both it is the same as in the equilibrium in c1). The payoff for the state $H$ seller has then also the same expression as in such equilibrium $p_{L}-c_{L}-\sum_{\tau=1}^{\infty}\left[\delta^{\tau-1} q_{B}(\tau)\left(\Pi_{l=1}^{\tau-1}\left(1-q_{B}(l)\right)\right)\right]\left(c_{H}-c_{L}\right)$, though its value will typically be different (since buyers may randomize with different probabilities): in particular, we can show it will be lower. This follows from the fact that, as we can see from (7.3), to sustain the state $L$ seller's randomization with an increasing price sequence $\left\{p_{H}(t)\right\}_{t \geqslant 1}$ buyers have to reject with higher probabilities $\left(q_{B}(\right.$.$) will$ be lower) and these are the only variables determining the state $H$ seller's payoff, as we see from the previous expression.

\section{Finite horizon:}

All the equilibria we obtained for the case of infinitely many trading dates remain (or are approximated by) equilibria when there is only a finite number of trading dates $(\mathbf{T} \geq 1)$. This is clear when the equilibrium in question involves a finite number of periods of trade; but even when there are infinite periods of trade, for example with infinite randomization on the part of buyers, for any $\mathbf{T}$ there is a payoff equivalent equilibrium where buyers randomize at each trading date.

To illustrate, consider the one-period $(\mathbf{T}=1)$ version of the model. In this case, rejection of a price leads to "no trade", thus to a zero payoff. It is easy to see that if $\alpha_{0}>\bar{\alpha}$, the unique equilibrium continues to yield trade at $p_{H}$ in both states. If $\alpha_{0}<\bar{\alpha}$, the unique equilibrium prescribes that the seller in state $L$ randomizes between $p_{H}$ and $p_{L}$ so as to induce the belief $\alpha_{1}=\bar{\alpha}$, while the buyers must accept the high price with probability $q_{B}(1)$ (where $q_{B}(1)$ is set at a level such that the seller in $L$ is exactly indifferent between charging $p_{L}$ and $p_{H}$ ). 
When $\mathbf{T}=2$, the equilibrium with $\alpha_{0}>\bar{\alpha}$ continues to have pooling on $p_{H}$ and immediate trade, with no delay. When $\alpha_{0}<\bar{\alpha}$, with $\mathbf{T}=2$ we continue to have as the unique equilibrium the one in which $q_{S}(1)$ is chosen to yield $\alpha_{1}=\bar{\alpha}$, while $q_{B}(1)$ and $q_{B}(2)$ are chosen to make the seller in state $L$ indifferent between charging $p_{L}$ and $p_{H}$ at $t=1$ and to (weakly) prefer $p_{H}$ at $t=2$; the information is then partially revealed only in period 1 .

We can also show that no other equilibria exist, in particular there is no equilibrium where both buyers and the seller in state $L$ randomize at each trading date: in that case in fact we must have $\alpha_{t}>\bar{\alpha}$ for all $t$, thus buyers at the terminal date accept $p_{H}$ for sure, and so the seller always proposes $p_{H}$ at $\mathbf{T}$, but then buyers cannot be indifferent between accepting and rejecting $p_{H}$ at $\mathbf{T}-1$.

We thus conclude that the qualitative properties of the set of equilibria are essentially the same when $\mathbf{T}<\infty$ and $\mathbf{T}=\infty$, our findings are not generated by a possible discontinuity at $\mathbf{T}=\infty$.

\section{Robustness of results in the oligopoly models:}

The robustness analysis can build, to a large extent, on the properties derived in this regard for the monopoly case. In particular, it is easy to see that the full and immediate revelation result of the model without clienteles for $n$ large enough is again found with a continuum of possible prices, though now there will be a continuum of such equilibria; also, for $n$ large enough no collusive equilibria exist. Analogously, the model with clienteles has equilibria with no or only partial information revelation, whatever is $n$. Similar findings are obtained in the corresponding finite horizon versions of these models. 


\section{References}

- Blouin, M. And R. Serrano (2001), "A Decentralized Market with Common Values Uncertainty: Non-Steady States", Review of Economic Studies 68, 323-346.

- Cripps, M. And J. M. Swinkels (2004), "Efficiency in Large Double Auctions," Mimeo, Washington University in St. Louis.

- Dubey, P., J. Geanakoplos and M. Shubik (1987), "The Revelation of Information in Strategic Market Games: a Critique of Rational Expectations Equilibrium", Journal of Mathematical Economics 6, 105-137.

- Forges, F. (1992), "Repeated Games of Incomplete Information: Non-0 Sum," chapter 6 in R. . Aumann and S. Hart (eds.) Handbook of Game Theory with Economic Applications (vol. I), North Holland, New York.

- Forges, F. and E. Minelli (1997), "Self-Fulfilling Mechanisms and Rational Expectations", Journal of Economic Theory 75, 388-406.

- Foster, D. and S. Viswanathan (1996), "Strategic Trading when Agents Forecast the Forecast of Others," Journal of Finance, 51, 1437-1478.

- Gale, D. (1987), "Limit Theorems for Markets with Sequential Bargaining", Journal of Economic Theory 43, 20-54.

- Grinblatt, M. And S. Ross (1985), "Market Power in a Securities Market with Endogenous Information", Quarterly Journal of Economics 100, 11431167.

- Gul, F. And A. Postlewaite (1992), "Asymptotic Efficiency in Large Exchange Economies with Asymmetric Information", Econometrica 60, 12731292.

- Gul, F., H. Sonnenschein and R. Wilson (1986), "Foundations of Dynamic Monopoly and the Coase Conjecture", Journal of Economic Theory, 39, 155-190.

- Holden, C. And A. Subrahmanyam (1992), "Long-Lived Private Information and Imperfect Competition," Journal of Finance, 47, 247-270. 
- Kyle, A. (1985), "Continuous Auctions and Insider Trading", Econometrica 53, 1315-1335.

- Kyle, A. (1989), "Informed Speculation with Imperfect Competition", Review of Economic Studies 56, 317-356.

- Laffont, J.J. And E. Maskin (1990), "The Efficient Market Hypothesis and Insider Trading on the Stock Market", Journal of Political Economy 98, 70-93.

- Medrano, L. A. And X. Vives (2001), "Strategic Behavior and Price Discovery," Rand Journal of Economics 32, 221-248.

- Mertens, J.-F., S. Sorin And S. Zamir (1994), "Repeated Games," working papers 9420, 9421 and 9422, CORE, Universitè Catholique de Louvain.

- Perry, M. And P. Reny (2003), "Toward a Strategic Foundation for Rational Expectations Equilibrium," Mimeo, University of Chicago.

- Pesendorfer, W. And J. M. Swinkels (1997), "The Loser's Curse and Information Aggregation in Common Values Auctions," Econometrica 65, $1247-1281$.

- Peters, M. (1991), "Ex Ante Price Offers in Matching Games: Non-Steady States", Econometrica 59, 1425-1454.

- Peters, M. And S. Severinov (2002), "Internet Trading Mechanisms and Rational Expectations," Mimeo, University of British Columbia.

- Radner, R. (1982), "Equilibrium under Uncertainty", Chapter 20 in Handbook of Mathematical Economics, vol. II, edited by K.J. Arrow and M.D. Intriligator. Amsterdam: North-Holland.

- Rustichini, A., M. Satterthwaite and S. Williams (1994), "Convergence to Efficiency in a Simple Market with Incomplete Information", Econometrica 62, 1041-1063.

- Satterthwaite, M. and S. R. Williams (2002), "The Optimality of a Simple Market Mechanism," Econometrica 70, 1841-1863. 
- Serrano, R. (2002), "Decentralized Information and the Walrasian Outcome: a Pairwise Meetings Market with Private Values", Journal of Mathematical Economics 38, 65-89.

- Serrano, R. and O. Yosha (1996), "Welfare Analysis of a Market with Pairwise Meetings and Asymmetric Information," Economic Theory 8, 167175.

- Shapley, L. And M. Shubik (1977), "Trade Using One Commodity as Means of Payment," Journal of Political Economy 85, 937-968.

- Shneyerov, A. And M. Satterthwaite (2003), "Convergence of a Dynamic Matching and Bargaining Market with Two-Sided Incomplete Information to Perfect Competition," Working paper 03-12, University of British Columbia.

- Vives, X. (1995), "The Speed of Information Revelation in a Financial Market Mechanism", Journal of Economic Theory 67, 178-204.

- Wolinsky, A. (1990), "Information Revelation in a Market with Pairwise Meetings", Econometrica 58, 1-23.

- Zamir, S. (1992), "Repeated Games of Incomplete Information: 0-Sum," chapter 5 in R. J. Aumann and S. Hart (eds.) Handbook of Game Theory with Economic Applications (vol. I), North Holland, New York. 


\title{
CESifo Working Paper Series
}

\author{
(for full list see www.cesifo.de)
}

1237 M. Hashem Pesaran, Davide Pettenuzzo, and Allan Timmermann, Forecasting Time Series Subject to Multiple Structural Breaks, July 2004

1238 Panu Poutvaara and Andreas Wagener, The Invisible Hand Plays Dice: Eventualities in Religious Markets, July 2004

1239 Eckhard Janeba, Moral Federalism, July 2004

1240 Robert S. Chirinko, Steven M. Fazzari, and Andrew P. Meyer, That Elusive Elasticity: A Long-Panel Approach to Estimating the Capital-Labor Substitution Elasticity, July 2004

1241 Hans Jarle Kind, Karen Helene Midelfart, Guttorm Schjelderup, Corporate Tax Systems, Multinational Enterprises, and Economic Integration, July 2004

1242 Vankatesh Bala and Ngo Van Long, International Trade and Cultural Diversity: A Model of Preference Selection, July 2004

1243 Wolfgang Eggert and Alfons J. Weichenrieder, On the Economics of Bottle Deposits, July 2004

1244 Sören Blomquist and Vidar Christiansen, Taxation and Heterogeneous Preferences, July 2004

1245 Rafael Lalive and Alois Stutzer, Approval of Equal Rights and Gender Differences in Well-Being, July 2004

1246 Paolo M. Panteghini, Wide vs. Narrow Tax Bases under Optimal Investment Timing, July 2004

1247 Marika Karanassou, Hector Sala, and Dennis J. Snower, Unemployment in the European Union: Institutions, Prices, and Growth, July 2004

1248 Engin Dalgic and Ngo Van Long, Corrupt Local Government as Resource Farmers: The Helping Hand and the Grabbing Hand, July 2004

1249 Francesco Giavazzi and Guido Tabellini, Economic and Political Liberalizations, July 2004

1250 Yin-Wong Cheung and Jude Yuen, An Output Perspective on a Northeast Asia Currency Union, August 2004

1251 Ralf Elsas, Frank Heinemann, and Marcel Tyrell, Multiple but Asymmetric Bank Financing: The Case of Relationship Lending, August 2004 
1252 Steinar Holden, Wage Formation under Low Inflation, August 2004

1253 Ngo Van Long and Gerhard Sorger, Insecure Property Rights and Growth: The Roles of Appropriation Costs, Wealth Effects, and Heterogeneity, August 2004

1254 Klaus Wälde and Pia Weiß, International Competition, Slim Firms and Wage Inequality, August 2004

1255 Jeremy S. S. Edwards and Alfons J. Weichenrieder, How Weak is the Weakest-Link Principle? On the Measurement of Firm Owners' Control Rights, August 2004

1256 Guido Tabellini, The Role of the State in Economic Development, August 2004

1257 François Larmande and Jean-Pierre Ponssard, EVA and the Controllability-congruence Trade-off: An Empirical Investigation, August 2004

1258 Vesa Kanniainen and Jenni Pääkkönen, Anonymous Money, Moral Sentiments and Welfare, August 2004

1259 Panu Poutvaara and Andreas Wagener, Why is the Public Sector More Labor-Intensive? A Distortionary Tax Argument, August 2004

1260 Lars P. Feld and Stefan Voigt, Making Judges Independent - Some Proposals Regarding the Judiciary, August 2004

1261 Joop Hartog, Hans van Ophem, and Simona Maria Bajdechi, How Risky is Investment in Human Capital?, August 2004

1262 Thomas Eichner and Rüdiger Pethig, Efficient Nonanthropocentric Nature Protection, August 2004

1263 David-Jan Jansen and Jakob de Haan, Look Who's Talking: ECB Communication during the First Years of EMU, August 2004

1264 David F. Bradford, The X Tax in the World Economy, August 2004

1265 Hans-Werner Sinn, Migration, Social Standards and Replacement Incomes. How to Protect Low-income Workers in the Industrialized Countries against the Forces of Globalization and Market Integration, August 2004

1266 Wolfgang Leininger, Fending off one Means Fending off all: Evolutionary Stability in Submodular Games, August 2004

1267 Antoine Bommier and Bertrand Villeneuve, Risk Aversion and the Value of Risk to Life, September 2004

1268 Harrie A. A. Verbon and Lex Meijdam, Too Many Migrants, Too Few Services: A Model of Decision-making on Immigration and Integration with Cultural Distance, September 2004 
1269 Thomas Eichner and Rüdiger Pethig, Economic Land Use, Ecosystem Services and Microfounded Species Dynamics, September 2004

1270 Federico Revelli, Performance Rating and Yardstick Competition in Social Service Provision, September 2004

1271 Gerhard O. Orosel and Klaus G. Zauner, Vertical Product Differentiation When Quality is Unobservable to Buyers, September 2004

1272 Christoph Böhringer, Stefan Boeters, and Michael Feil, Taxation and Unemployment: An Applied General Equilibrium Approach, September 2004

1273 Assaf Razin and Efraim Sadka, Welfare Migration: Is the Net Fiscal Burden a Good Measure of its Economics Impact on the Welfare of the Native-Born Population?, September 2004

1274 Tomer Blumkin and Volker Grossmann, Ideological Polarization, Sticky Information, and Policy Reforms, September 2004

1275 Katherine Baicker and Nora Gordon, The Effect of Mandated State Education Spending on Total Local Resources, September 2004

1276 Gabriel J. Felbermayr and Wilhelm Kohler, Exploring the Intensive and Extensive Margins of World Trade, September 2004

1277 John Burbidge, Katherine Cuff and John Leach, Capital Tax Competition with Heterogeneous Firms and Agglomeration Effects, September 2004

1278 Joern-Steffen Pischke, Labor Market Institutions, Wages and Investment, September 2004

1279 Josef Falkinger and Volker Grossmann, Institutions and Development: The Interaction between Trade Regime and Political System, September 2004

1280 Paolo Surico, Inflation Targeting and Nonlinear Policy Rules: The Case of Asymmetric Preferences, September 2004

1281 Ayal Kimhi, Growth, Inequality and Labor Markets in LDCs: A Survey, September 2004

1282 Robert Dur and Amihai Glazer, Optimal Incentive Contracts for a Worker who Envies his Boss, September 2004

1283 Klaus Abberger, Nonparametric Regression and the Detection of Turning Points in the Ifo Business Climate, September 2004

1284 Werner Güth and Rupert Sausgruber, Tax Morale and Optimal Taxation, September 2004 
1285 Luis H. R. Alvarez and Erkki Koskela, Does Risk Aversion Accelerate Optimal Forest Rotation under Uncertainty?, September 2004

1286 Giorgio Brunello and Maria De Paola, Market Failures and the Under-Provision of Training, September 2004

1287 Sanjeev Goyal, Marco van der Leij and José Luis Moraga-González, Economics: An Emerging Small World?, September 2004

1288 Sandro Maffei, Nikolai Raabe and Heinrich W. Ursprung, Political Repression and Child Labor: Theory and Empirical Evidence, September 2004

1289 Georg Götz and Klaus Gugler, Market Concentration and Product Variety under Spatial Competition: Evidence from Retail Gasoline, September 2004

1290 Jonathan Temple and Ludger Wößmann, Dualism and Cross-Country Growth Regressions, September 2004

1291 Ravi Kanbur, Jukka Pirttilä and Matti Tuomala, Non-Welfarist Optimal Taxation and Behavioral Public Economics, October 2004

1292 Maarten C. W. Janssen, José Luis Moraga-González and Matthijs R. Wildenbeest, Consumer Search and Oligopolistic Pricing: An Empirical Investigation, October 2004

1293 Kira Börner and Christa Hainz, The Political Economy of Corruption and the Role of Financial Institutions, October 2004

1294 Christoph A. Schaltegger and Lars P. Feld, Do Large Cabinets Favor Large Governments? Evidence from Swiss Sub-Federal Jurisdictions, October 2004

1295 Marc-Andreas Mündler, The Existence of Informationally Efficient Markets When Individuals Are Rational, October 2004

1296 Hendrik Jürges, Wolfram F. Richter and Kerstin Schneider, Teacher Quality and Incentives: Theoretical and Empirical Effects of Standards on Teacher Quality, October 2004

1297 David S. Evans and Michael Salinger, An Empirical Analysis of Bundling and Tying: Over-the-Counter Pain Relief and Cold Medicines, October 2004

1298 Gershon Ben-Shakhar, Gary Bornstein, Astrid Hopfensitz and Frans van Winden, Reciprocity and Emotions: Arousal, Self-Reports, and Expectations, October 2004

1299 B. Zorina Khan and Kenneth L. Sokoloff, Institutions and Technological Innovation During Early Economic Growth: Evidence from the Great Inventors of the United States, 1790 - 1930, October 2004

1300 Piero Gottardi and Roberto Serrano, Market Power and Information Revelation in Dynamic Trading, October 2004 